\title{
东北杏种质资源多样性及其地理变化
}

\author{
徐 豪 ${ }^{*}$ 刘明国 ${ }^{* *}$ 董胜君 吴月亮 张皓凯
}

沈阳农业大学林学院, 沈阳 110161

摘 要 东北杏(Armeniaca mandshurica) 是集观赏、经济、用材于一体的重要树种, 长期以来主要处于野生和半野生状态, 鲜 有相关研究报道。该研究对东北杏主要分布区内种质资源状况开展了调查, 选择来自辽宁、吉林与黑龙江的47份典型种质进 行了 22 个定量描述性状和 7 个定性描述性状的观测, 旨在为该树种的种质资源收集、评价与保护提供重要参考。采用变异系 数等指标分析定量描述性状多样性, 使用频率分布等指标分析定性描述性状多样性。通过趋势面方法分析定量描述性状的地 理变化规律。利用99对SSR引物对47份东北杏种质进行PCR扩增, 应用遗传相似系数分析东北杏种质的遗传多样性。基于表 型性状和SSR分子标记采用聚类分析方法分别对种质进行分类。东北杏不同种质间呈现出较高的表型多样性, 其中19个定量 描述性状指标的变异系数在 $9.40 \%-55.98 \%$ 之间, 变异系数最大的为小枝长度, 变异系数最小的为种仁宽; 7 个定性描述性状 的Shannon-Wiener指数在 $0.58-1.22$ 之间。由于调查区域的地理位置与主要气候因子间存在着显著的相关性, 东北杏种质的定 量描述性状与其地理位置有着密切的关系。其中, 小枝长度呈由东向西逐渐增大的梯度变化, 小枝粗度、种子质量呈由北向 南逐渐增大的梯度变化, 果柄长呈由东北向西南逐渐增大的梯度变化; 小枝长度、果柄长与海拔呈正相关关系, 小枝粗度与 海拔呈负相关关系, 种子质量与海拔相关性很小。基于 26 个表型性状进行系统聚类, 将 47 份东北杏种质分为 4 类, 分类结果主 要体现了东北杏种质特征的差别, 同时也在一定程度上体现了种质产地的效应; 基于遗传相似系数进行聚类分析, 将47份东 北杏种质也分为4类, 分类结果体现了种质产地效应; 卡方检验表明, 两种聚类结果相关性不显著, 外在环境是影响东北杏表 型变异的重要因素。

关键词 东北杏; 多样性; 表型性状; 地理变化; SSR标记

徐豪, 刘明国, 董胜君, 吴月亮, 张皓凯 (2019). 东北杏种质资源多样性及其地理变化. 植物生态学报, 43, 585-600. DOI: 10.17521/cjpe.2019.0060

\section{Diversity and geographical variations of germplasm resources of Armeniaca mandshurica}

\author{
XU Hao , LIU Ming-Guo **, DONG Sheng-Jun, WU Yue-Liang, and ZHANG Hao-Kai \\ College of Forestry, Shenyang Agricultural University, Shenyang 110161, China
}

\begin{abstract}
Aims Armeniaca mandshurica is an important species which serves the need of ornamental, wood and other economical uses. This species has been in wild or semi-wild state for a long time and few studies about this species have been conducted. This paper aimed to provide an important reference for the collection, evaluation and protection of germplasm resources of $A$. mandshurica.
\end{abstract}

Methods The status of the germplasm resources in the main distribution area of $A$. mandshurica was investigated. In total, 47 typical sample trees from Liaoning, Jilin and Heilongjiang Provinces were selected. For each tree, 22 quantitative traits and 7 qualitative traits were measured. The diversity of quantitative traits was represented by indicators such as coefficient of variation, and the diversity of qualitative traits was represented by indicators such as frequency distribution. Trend surface analysis was used to explore the geographical variation in the quantitative traits. A total of 115 pairs of SSR primers were used for PCR amplification for 47 A. mandshurica germplasms, and the genetic diversity of $A$. mandshurica germplasms was analyzed using genetic similarity coefficient. Germplasms were classified by cluster analysis based on phenotypic traits and SSR markers separately.

Important findings High phenotypic diversity was found among different germplasms in A. mandshurica. The coefficients of variation $(C V)$ of the 19 quantitative traits ranged from $9.40 \%$ to $55.98 \%$. Among the 19 traits, twig length had the highest $C V$ and kernel width had the lowest $C V$. The Shannon-Wiener index of 7 qualitative traits

收稿日期Received: 2019-03-18 接受日期Accepted: 2019-05-15

基金项目: 辽宁特聘教授基金(2012)。Supported by the Distinguished Professor Foundation Project of Liaoning Province, China.

* E-mail: 2017220539@stu.syau.edu.cn

** 通信作者Corresponding author (liumingguo916@163.com) 
ranged from 0.58 to 1.22 . Due to the significant correlation between geographical locations and main climatic factors within the study area, the quantitative traits of $A$. mandshurica germplasms were closely related to their geographical locations. Among them, twig length increased from east to west, twig thickness and seed mass increased from north to south, and fruit handle length increased from northeast to southwest. Twig length and fruit handle length were positively correlated with altitude, twig thickness was negatively correlated with altitude, and seed mass was not correlated with altitude. Clustering analysis based on 26 phenotypic traits showed that the $47 \mathrm{~A}$. mandshurica germplasms could be divided into 4 categories, which mainly reflected the difference of the germplasm characteristics in A. mandshurica and to some extent also reflected the difference of germplasm productions. Clustering analysis based on genetic similarity coefficients showed that the $47 \mathrm{~A}$. mandshurica germplasms were also divided into 4 categories, which reflected the difference of germplasm productions. Chi-square test showed that the correlation between the two clustering results was not significant, and that the external environment was the key factor affecting phenotypic variations in A. mandshurica.

Key words Armeniaca mandshurica; diversity; phenotypic traits; geographical variations; SSR markers

Xu H, Liu MG, Dong SJ, Wu YL, Zhang HK (2019). Diversity and geographical variations of germplasm resources of Armeniaca mandshurica. Chinese Journal of Plant Ecology, 43, 585-600. DOI: 10.17521/cjpe.2019.0060

东北杏(Armeniaca mandshurica) 为萻薇科杏属 植物, 主要分布于我国黑龙江、吉林和辽宁的东部 地区，在朝鲜的中北部和俄罗斯南乌苏里地区也有 分布。东北杏用途很广, 是集观赏、经济、用材于 一身的重要树种(庞振伟等, 2001; 王利兵, 2010)。目 前该树种尚未得到充分开发, 主要处于野生和半野 生状态, 除了少量园林绿化栽培外, 其他利用方式 鲜见报道。同时由于缺乏保护措施, 其资源破坏严 重, 数量日渐减少。

种质资源是林木改良的物质基础, 同时也是遗 传学、分类学、生物学等理论研究的重要材料, 进 行种质资源调查、评价是对其合理保护、利用的前 提。目前, 林木种质资源调查、评价研究主要集中 于主要经济林树种(Wu et al., 2007; 刘小利等, 2015; 刘胤等, 2016)和用材林树种(Liu et al., 1997; Wan \& Zhang, 2013; 郭琪等, 2019)。山杏是野生的蓄薇科 杏属植物统称, 相关研究在西伯利亚杏(Armeniaca sibirica)上比较活跃，已从形态标记(李明等, 2011b; 尹健等, 2015)、蛋白质和酶标记(刘明国等, 2006; 李 明等, 2011a)、孢粉学(刘明国等, 2015)及SSR分子标 记(Wang et al., 2014; 金玲等, 2018)等方面开展了 种质资源评价和分类研究。但作为山杏重要组成树 种的东北杏, 未见相关研究报道。

遗传多样性是指物种种内基因组成的多样性, 不同的遗传多样性研究及检测方法存在差异, 可从 形态学、细胞学及DNA分子等水平上进行, 其中表 型测定是最简单和最直接的方法(李文英和顾万春, 2005)。表型性状是由基因型和环境共同作用的结果, 表型多样性是环境多样性和遗传多样性的综合体现,
通过对表型变异程度和地理变化规律的研究, 不仅 可以揭示物种适应和进化的方式, 而且有助于了解 种群遗传变异的大小, 这也是遗传育种工作的基础 (苏世平等, 2013; 杨晓霞等, 2016)。近年来, 对野杏 (Armeniaca vulgaris var. ansu)(曹倩等, 2015)、枫香 树(Liquidambar formosana)(何庆海等, 2018)、尾叶 樱桃(Cerasus dielsiana)(朱弘等, 2018)等植物的表 型变异特征和 Azadirachta indica (Kundu \& Tigerstedt, 1997)、无患子(Sapindus mukorossi)(邵文豪 等, 2013)、乌饭树(Vaccinium bracteatum)(刘仁林等, 2016)等树种的表型地理变异已有较多研究报道。

本研究以辽宁、吉林和黑龙江的47份东北杏种 质为试验材料, 对其 22 个定量描述性状和 7 个定性 描述性状进行了观测, 并进行了SSR 分子标记试验, 在此基础上分析了种质资源多样性及其地理变化, 以了解性状地理分布格局, 揭示变异特点、变异程 度及其与地理环境的关系, 旨在为收集、评价与保 护东北杏种质资源提供重要参考, 同时为该树种的 良种选育工作提供科学依据。

\section{1 材料和方法}

\section{1 研究区域自然概况}

本研究调查区域包括辽宁风城市、本溪县、桓 仁县、新宾县、清原县、沈阳市, 吉林抚松县、磐 石市、华甸市、敦化市、吉林市, 黑龙江宁安市、 尚志市、鸡西市和阿城区等地。调查区域的年平均 气温为3.4-8.5 ${ }^{\circ} \mathrm{C}, 7$ 月最高气温平均为 $25.3-29.0{ }^{\circ} \mathrm{C}$, 1 月最低气温平均为 $-25.4--14.9{ }^{\circ} \mathrm{C}$, 年降水量为 530.2-1 $077.8 \mathrm{~mm}$ 。地貌类型为中低山地、低山丘 
陵和平原, 土壤类型主要有棕壤、暗棕壤、白浆土、 草甸土等，植被属长白植物区系。

\section{2 试验材料}

在2016年6-8月, 开展了对上述 15 个地区的东 北杏种质资源调查, 共选择47份东北杏典型种质 (表1)进行表型性状观测。

\section{3 表型性状观测内容与方法}

参照《中国果树志: 杏卷》(张加延和张创, 2003) 和《山杏种质资源调查及评价技术规程》 (吴月亮等, 2015), 对7个定性描述性状指标、22个定量描述性 状指标进行观测(表2)。

观测指标包括树体、小枝、叶片、果、种子、 种仁6个方面。树体性状: 测量树高、胸径、冠幅、 主枝基角; 小枝性状: 选择种质东、南、西、北4个 方向的外围中、上部当年生枝条, 测量其长度、粗 度，记载其色泽; 叶片性状: 选择种质东、南、西、 北 4 个方向的当年生枝条各 1 个, 从梢端数第 5-7片
成熟叶, 测量其叶长、叶宽、叶柄长, 记载叶表、叶 背被毛情况, 叶基形状, 叶缘形状和腺体数量; 果 实性状: 果实成熟后, 在树体东、南、西、北 4 个方 向的小枝上各选取10-20个健康、无病虫害的果实, 分别测量果长、果宽、果厚、单果质量、果柄长, 记 载果实形状; 种子性状: 测量种子长、种子宽、种 子厚、种子质量; 种仁性状: 测量种仁长、种仁宽、 种仁厚、种仁质量。

\subsection{SSR分子标记试验}

在2016年6月中旬, 采集47份供试东北杏种质 向阳面一年生枝条上的叶片，放入液氮罐中速冻， 带回实验室, 置于 $-80{ }^{\circ} \mathrm{C}$ 超低温冰箱中备用。

试验步骤包括DNA提取、SSR 引物篮选、PCR 反应体系及扩增程序、聚丙烯酰胺凝胶电泳检测及 数据的读取，具体参照金玲等(2018)的方法。

\section{5 数据统计分析}

使用SPSS 20.0软件对所得表型性状数据进行

表1 供试东北杏种质的地理位置

Table 1 Geographic locations of sampled Armeniaca mandshurica germplasms

\begin{tabular}{|c|c|c|c|c|c|c|c|}
\hline $\begin{array}{l}\text { 种质编号 } \\
\text { Germplasm No. }\end{array}$ & $\begin{array}{l}\text { 地点 } \\
\text { Site }\end{array}$ & $\begin{array}{c}\text { 海拔 } \\
\text { Altitude (m) }\end{array}$ & $\begin{array}{c}\text { 经纬度 } \\
\text { Longitude }(\mathrm{E}) \\
\text { and Latitude }(\mathrm{N})\end{array}$ & $\begin{array}{l}\text { 种质编号 } \\
\text { Germplasm No. }\end{array}$ & $\begin{array}{l}\text { 地点 } \\
\text { Site }\end{array}$ & $\begin{array}{c}\text { 海拔 } \\
\text { Altitude (m) }\end{array}$ & $\begin{array}{c}\text { 经纬度 } \\
\text { Longitude (E) } \\
\text { and Latitude (N) }\end{array}$ \\
\hline 701 & 凤城 Fengcheng & 185.6 & $123.95^{\circ}, 40.42^{\circ}$ & 747 & 桦甸 Huadian & 268.5 & $127.04^{\circ}, 42.98^{\circ}$ \\
\hline 702 & 凤城 Fengcheng & 187.6 & $123.95^{\circ}, 40.42^{\circ}$ & 748 & 敦化 Dunhua & 495.0 & $128.22^{\circ}, 43.38^{\circ}$ \\
\hline 703 & 凤城 Fengcheng & 185.4 & $123.95^{\circ}, 40.42^{\circ}$ & 749 & 敦化 Dunhua & 509.6 & $128.22^{\circ}, 43.38^{\circ}$ \\
\hline 704 & 本溪 Benxi & 406.0 & $123.96^{\circ}, 40.88^{\circ}$ & 750 & 敦化 Dunhua & 517.3 & $128.22^{\circ}, 43.38^{\circ}$ \\
\hline 705 & 本溪 Benxi & 405.8 & $123.96^{\circ}, 40.88^{\circ}$ & 751 & 敦化 Dunhua & 598.8 & $128.54^{\circ}, 43.41^{\circ}$ \\
\hline 706 & 本溪 Benxi & 406.3 & $123.96^{\circ}, 40.88^{\circ}$ & 752 & 敦化 Dunhua & 599.1 & $128.54^{\circ}, 43.41^{\circ}$ \\
\hline 707 & 桓仁 Huanren & 277.6 & $125.37^{\circ}, 41.25^{\circ}$ & 753 & 敦化 Dunhua & 595.3 & $128.54^{\circ}, 43.41^{\circ}$ \\
\hline 708 & 桓仁 Huanren & 272.6 & $125.37^{\circ}, 41.25^{\circ}$ & 755 & 吉林 Jilin & 301.4 & $126.80^{\circ}, 43.97^{\circ}$ \\
\hline 709 & 桓仁 Huanren & 283.3 & $125.37^{\circ}, 41.25^{\circ}$ & 756 & 吉林 Jilin & 302.2 & $126.80^{\circ}, 43.97^{\circ}$ \\
\hline 710 & 新宾 Xinbin & 387.1 & $125.10^{\circ}, 41.77^{\circ}$ & 757 & 吉林 Jilin & 303.7 & $126.80^{\circ}, 43.97^{\circ}$ \\
\hline 711 & 新宾 Xinbin & 416.5 & $125.10^{\circ}, 41.77^{\circ}$ & 758 & 吉林 Jilin & 200.0 & $126.55^{\circ}, 43.85^{\circ}$ \\
\hline 712 & 新宾 Xinbin & 419.1 & $125.10^{\circ}, 41.77^{\circ}$ & 772 & 宁安 Ningan & 263.8 & $129.52^{\circ}, 44.42^{\circ}$ \\
\hline 713 & 清原 Qingyuan & 315.7 & $124.81^{\circ}, 42.34^{\circ}$ & 773 & 宁安 Ningan & 262.2 & $129.52^{\circ}, 44.42^{\circ}$ \\
\hline 714 & 清原 Qingyuan & 318.7 & $124.81^{\circ}, 42.34^{\circ}$ & 774 & 宁安 Ningan & 268.6 & $129.52^{\circ}, 44.42^{\circ}$ \\
\hline 715 & 清原 Qingyuan & 315.7 & $124.81^{\circ}, 42.34^{\circ}$ & 775 & 宁安 Ningan & 279.6 & $129.52^{\circ}, 44.42^{\circ}$ \\
\hline 724 & 沈阳 Shenyang & 60.0 & $123.57^{\circ}, 41.82^{\circ}$ & 776 & 尚志 Shangzhi & 327.6 & $127.55^{\circ}, 45.27^{\circ}$ \\
\hline 729 & 沈阳 Shenyang & 58.0 & $123.55^{\circ}, 41.82^{\circ}$ & 777 & 鸡西 Jixi & 303.6 & $130.52^{\circ}, 45.21^{\circ}$ \\
\hline 730 & 沈阳 Shenyang & 65.0 & $123.55^{\circ}, 41.82^{\circ}$ & 778 & 鸡西 Jixi & 282.6 & $130.54^{\circ}, 45.18^{\circ}$ \\
\hline 741 & 抚松 Fusong & 461.9 & $127.20^{\circ}, 42.34^{\circ}$ & 779 & 鸡西 Jixi & 372.4 & $130.69^{\circ}, 45.02^{\circ}$ \\
\hline 742 & 抚松 Fusong & 460.9 & $127.20^{\circ}, 42.34^{\circ}$ & 783 & 阿城 Acheng & 243.0 & $127.05^{\circ}, 45.44^{\circ}$ \\
\hline 743 & 抚松 Fusong & 449.7 & $127.20^{\circ}, 42.34^{\circ}$ & 784 & 阿城 Acheng & 262.0 & $127.05^{\circ}, 45.43^{\circ}$ \\
\hline 744 & 磐石 Panshi & 399.2 & $126.06^{\circ}, 42.86^{\circ}$ & 785 & 阿城 Acheng & 262.1 & $127.05^{\circ}, 45.43^{\circ}$ \\
\hline 745 & 磐石 Panshi & 402.5 & $126.06^{\circ}, 42.86^{\circ}$ & 786 & 阿城 Acheng & 216.4 & $127.06^{\circ}, 45.44^{\circ}$ \\
\hline 746 & 磐石 Panshi & 401.3 & $126.06^{\circ}, 42.86^{\circ}$ & & & & \\
\hline
\end{tabular}


统计与分析, 分别计算47份供试东北杏种质定量描 述性状的平均值 $(\bar{X})$ 、标准偏差 $(S D)$ 、极小值 $(M i n)$ 、 极大值 $(M a x)$ 、变异系数 $(C V=S D / \bar{X})$ 和 $K-S$ 值, 并 对定性描述性状进行频率统计、计算 ShannonWiener指数 $\left(H^{\prime}\right), H^{\prime}$ 的计算参照王永康等(2014)的方 法。通过Pearson系数分析法研究定量描述性状与地 理位置之间的相关关系, 采用 $\mathrm{R}$ 3.3.2软件对定量描 述性状进行多项式线性回归分析，使用Surfer软件 分析定量描述性状的地理变化规律。基于 26 个表型 性状, 运用R 3.3.2对47份东北杏种质进行主成分分 析。基于主成分得分值, 利用平方欧氏距离, 采用离 差平方和法(Ward)进行系统聚类。

使用Cervus 3.0软件计算SSR标记各位点的多
态性信息含量 $\left(P I C=1-\sum P_{j}^{2}\right.$, 其中 $P_{j}^{2}$ 为第 $j$ 个基 因的频率); 按照Nei和 Li (1979)的方法计算种质间 的遗传相似系数 $(G S): G S=2 N_{i j} /\left(N_{i}+N_{j}\right)$, 式中 $N_{i}$ 和 $N_{j}$ 为 $i$ 和 $j$ 种质的谱带数, $N_{i j}$ 为 $i$ 和 $j$ 种质共有的谱带数。 基于遗传相似系数, 利用NTSYS 2.1软件, 采用非 加权组平均法(UPGMA)对47份东北杏种质进行聚 类分析。

\section{2 结果和分析}

\section{1 东北杏种质资源表型性状多样性}

\subsection{1 定性描述性状频率分布及多样性指数}

对东北杏种质的 7 个定性描述性状进行频率统 计及变异分析(表3), 由表可知，小枝色泽以绿色为

表2 东北杏种质表型性状及其描述

Table 2 Phenotypic traits and their description of Armeniaca mandshurica germplasms

\begin{tabular}{|c|c|c|}
\hline 序号 No. & 性状 Traits & 表型性状描述 Description of phenotypic traits \\
\hline 1 & 小枝色泽 Twig color & 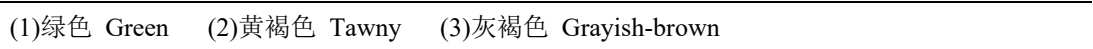 \\
\hline 2 & 叶背被毛 Leaf back fuzzed & (1)有 Hairy (2)无 Glabrous \\
\hline 3 & 叶表被毛 Leaf surface fuzzed & (1)有 Hairy (2)无 Glabrous \\
\hline 4 & 叶基形状 Leaf base shape & (1)宽楔形 Wide wedge (2)圆形 Round (3)窄楔形 Narrow wedge \\
\hline 5 & 叶缘形状 Leaf edge shape & (1)锐重锯齿 Sharp double sawtooth (2)钝重锯齿 Blunt double sawtooth \\
\hline 6 & 腺体数量 Number of glands & $\begin{array}{lll}\text { (1) } 1 \text { 个 One } & \text { (2) } 2 \text { 个 Two (3)无 Zero }\end{array}$ \\
\hline 7 & 果实形状 Fruit shape & $\begin{array}{l}\text { (1)球形 Sphericity (2)扁球形 Flat sphericity (3)扁长球形 Prolate sphericity } \\
\text { (4)扁宽球形 Flat and broad sphericity (5)长球形 Long sphericity }\end{array}$ \\
\hline 8 & 树高 Tree height & 树木从根颈到树梢之间的距离 The distance between the treetop and the root neck of tree \\
\hline 9 & 胸径 Diameter at breast height & 树干 $1.3 \mathrm{~m}$ 高度处的直径 Diameter of the trunk at $1.3 \mathrm{~m}$ height \\
\hline 10 & 冠幅 Crown diameter & $\begin{array}{l}\text { 树冠南北和东西方向宽度的平均值 The average value of the north-south and east-west width of tree } \\
\text { crown }\end{array}$ \\
\hline 11 & 主枝基角 Main branch base angle & 主枝与中心干之间的分枝角度 Angle between the main branch and the center stem of tree \\
\hline 12 & 小枝长度 Twig length & 一年生枝平均长度 Average length of annual branches \\
\hline 13 & 小枝粗度 Twig width & 一年生枝平均粗度 Average width of annual branches \\
\hline 14 & 叶长 Leaf length & 从叶基切线至叶尖顶部的长度 Length from the tangent of leaf base to the top of leaf tip \\
\hline 15 & 叶宽 Leaf width & 叶片最宽处的长度 The length of the blade at its widest point \\
\hline 16 & 叶柄长 Petiole length & 叶柄的长度 Length of petiole \\
\hline 17 & 单果质量 Single fruit mass & 单个成熟果实的质量 The mass of single ripe fruit \\
\hline 18 & 果长 Fruit length & 成熟果实从顶部到底部的最大距离 Maximum distance from top to bottom of ripe fruit \\
\hline 19 & 果宽 Fruit width & 成熟果实两条缝合线之间的最大距离 Maximum distance between two sutures of ripe fruit \\
\hline 20 & 果厚 Fruit thickness & 成熟果实腹面观时的最大距离 Maximum distance from the ventral view of ripe fruit \\
\hline 21 & 果柄长 Fruit handle length & 果柄的长度 Length of fruit handle \\
\hline 22 & 种子质量 Seed mass & 单个成熟种子的质量 The mass of single ripe seed \\
\hline 23 & 种子长 Seed length & 成熟种子从顶部到底部的最大距离 Maximum distance from top to bottom of ripe seed \\
\hline 24 & 种子宽 Seed width & 成熟种子脊背到缝翅的最大距离 Maximum distance from ridge to sewed wing of ripe seed \\
\hline 25 & 种子厚 Seed thickness & 成熟种子腹面观时的最大距离 Maximum distance from the ventral view of ripe seed \\
\hline 26 & 种仁质量 Kernel mass & 单个成熟种仁的质量 The mass of single mature kernel \\
\hline 27 & 种仁长 Kernel length & 成熟种仁从顶部到底部的最大距离 Maximum distance from top to bottom of ripe kernel \\
\hline 28 & 种仁宽 Kernel width & 成熟种仁两条缝合线之间的最大距离 Maximum distance between two sutures of ripe kernel \\
\hline 29 & 种仁厚 Kernel thickness & 成熟种仁腹面观时的最大距离 Maximum distance from the ventral view of ripe kernel \\
\hline
\end{tabular}

www.plant-ecology.com 
主(80.85\%); 叶背、叶表均以被毛为主, 分布频率分 别为 $74.47 \%$ 和 $68.09 \%$; 叶基形状以宽楔形为主 (74.47\%); 叶缘可分为锐重锯齿和针重锯齿, 两种 类型分布频率相差不大，分别为 $51.06 \%$ 和 $48.94 \%$; 叶柄腺体数量分为 1 个 $(34.04 \%) 、 2$ 个 $(40.43 \%)$ 和无 (25.53\%) 三类, 其中叶柄具有 2 个腺体的种质较多; 果实以扁球形为主 $(53.19 \%)$ 。

从Shannon-Wiener多样性指数来看, 不同定性 描述性状多样性之间差异明显, 范围在0.57-1.22之 间。其中, 果实形状、腺体数量多样性指数较大, 分
别为 1.22 和 1.08 (表 3$)$ 。

\subsection{2定量描述性状的分布特征及变异程度}

表 4 为东北杏 19 个定量描述性状的 $K-S$ 正态性分 布检验和变异程度分析结果, 树高、胸径和冠幅 3 个 定量描述性状受树龄影响较大, 未进行相应的统计 分析。由表 4 可知, 除了果柄长度外, 其余 18 个定量 描述性状的 $p$ 值均大于 0.05 , 表明这些性状呈正态 分布。

由表4可以看出，19个定量描述性状中，小枝长 度、果柄长和单果质量的变异系数较大, 分别为

表3 东北杏种质定性描述性状频率分布及多样性指数

Table 3 Frequency distribution and diversity index of the qualitative traits of Armeniaca mandshurica germplasms.

\begin{tabular}{|c|c|c|c|c|c|c|c|}
\hline \multirow{2}{*}{$\begin{array}{l}\text { 序号 } \\
\text { No. }\end{array}$} & \multirow{2}{*}{$\begin{array}{l}\text { 性状 } \\
\text { Traits }\end{array}$} & \multicolumn{5}{|c|}{ 频率分布 Frequency distribution (\%) } & \multirow{2}{*}{$\begin{array}{l}\text { Shannon-Wiener 多样性指数 } \\
\text { Shannon-Wiener diversity index }\end{array}$} \\
\hline & & 1 & 2 & 3 & 4 & 5 & \\
\hline 1 & 小枝色泽 Twig color & 80.85 & 14.89 & 4.26 & & & 0.59 \\
\hline 2 & 叶背被毛 Leaf back fuzzed & 74.47 & 25.53 & & & & 0.57 \\
\hline 3 & 叶表被毛 Leaf surface fuzzed & 68.09 & 31.91 & & & & 0.63 \\
\hline 4 & 叶基形状 Leaf base shape & 74.47 & 23.40 & 2.13 & & & 0.64 \\
\hline 5 & 叶缘形状 Leaf edge shape & 51.06 & 48.94 & & & & 0.69 \\
\hline 6 & 腺体数量 Number of glands & 34.04 & 40.43 & 25.53 & & & 1.08 \\
\hline 7 & 果实形状 Fruit shape & 23.41 & 53.19 & 14.89 & 6.38 & 2.13 & 1.22 \\
\hline
\end{tabular}

表4 东北杏种质定量描述性状的基本数据统计及 $K-S$ 检验

Table 4 Basic statistics and $K-S$ test of the quantitative traits of Armeniaca mandshurica germplasms.

\begin{tabular}{|c|c|c|c|c|c|c|c|}
\hline $\begin{array}{l}\text { 性状 } \\
\text { Traits } \\
\end{array}$ & $\begin{array}{c}\text { 极小值 } \\
\text { Min }\end{array}$ & $\begin{array}{c}\text { 极大值 } \\
\operatorname{Max}\end{array}$ & $\begin{array}{c}\text { 平均值 } \\
\bar{X} \\
\end{array}$ & $\begin{array}{c}\text { 标准偏差 } \\
S D\end{array}$ & $\begin{array}{c}\text { 变异系数 } \\
C V\end{array}$ & $\begin{array}{c}K-S \text { 值 } \\
K-S \text { value } \\
\end{array}$ & $\begin{array}{c}\text { 显著性 } \\
p \\
\end{array}$ \\
\hline 主枝基角 MBBA $\left(^{\circ}\right)$ & 18.00 & 51.00 & 33.60 & 7.04 & 0.2096 & 0.833 & 0.491 \\
\hline 小枝长度 $\mathrm{TL}(\mathrm{cm})$ & 10.23 & 120.00 & 59.82 & 33.49 & 0.5598 & 0.622 & 0.835 \\
\hline 小枝粗度 TW (mm) & 1.19 & 3.18 & 2.02 & 0.58 & 0.2868 & 0.897 & 0.397 \\
\hline 叶长 LL (mm) & 76.59 & 122.53 & 98.08 & 11.20 & 0.1142 & 0.822 & 0.509 \\
\hline 叶宽 LW (mm) & 44.96 & 78.46 & 62.36 & 7.34 & 0.1177 & 0.289 & 1.000 \\
\hline 叶柄长 PL (mm) & 18.48 & 45.29 & 30.25 & 6.19 & 0.2048 & 0.745 & 0.636 \\
\hline 单果质量 SFM (g) & 1.83 & 8.70 & 4.44 & 1.55 & 0.3477 & 0.971 & 0.302 \\
\hline 果长 FL (mm) & 15.17 & 24.93 & 20.38 & 2.31 & 0.1133 & 0.447 & 0.988 \\
\hline 果宽 FW (mm) & 12.92 & 26.16 & 19.92 & 2.72 & 0.1365 & 1.031 & 0.238 \\
\hline 果厚 FT (mm) & 10.65 & 24.06 & 17.49 & 2.89 & 0.1651 & 0.816 & 0.518 \\
\hline 种子质量 SM (g) & 0.58 & 1.45 & 1.01 & 0.24 & 0.2352 & 0.736 & 0.650 \\
\hline 种子长 SL (mm) & 13.11 & 24.01 & 16.51 & 1.95 & 0.1181 & 1.052 & 0.218 \\
\hline 种子宽 SW (mm) & 11.57 & 20.87 & 14.46 & 1.57 & 0.1085 & 0.914 & 0.374 \\
\hline 种子厚 ST (mm) & 8.66 & 15.72 & 10.34 & 1.16 & 0.1121 & 0.981 & 0.291 \\
\hline 种仁质量 KM (g) & 0.14 & 0.40 & 0.29 & 0.06 & 0.1936 & 0.572 & 0.898 \\
\hline 种仁长 KL (mm) & 8.65 & 13.59 & 11.27 & 1.06 & 0.0944 & 0.793 & 0.556 \\
\hline 种仁宽 KW (mm) & 6.68 & 11.11 & 8.59 & 0.81 & 0.0940 & 0.886 & 0.412 \\
\hline 种仁厚 KT (mm) & 4.21 & 7.69 & 5.71 & 0.82 & 0.1439 & 0.520 & 0.950 \\
\hline 果柄长 FHL (mm) & 3.24 & 14.52 & 7.04 & 2.87 & 0.4071 & 1.503 & 0.022 \\
\hline
\end{tabular}

$C V$, coefficient of variation; Max, maximum; Min, minimum; $S D$, standard deviation; $\bar{X}$, mean; FHL, fruit handle length; FL, fruit length; FT, fruit thickness; FW, fruit width; KL, kernel length; KM, kernel mass; KT, kernel thickness; KW, kernel width; LL, leaf length; LW, leaf width; MBBA, main branch base angle; PL, petiole length; SFM, single fruit mass; SL, seed length; SM, seed mass; ST, seed thickness; SW, seed width; TL, twig length; TW, twig width. 
$55.98 \%$ 、 $40.71 \%$ 和 $34.77 \%$, 种仁质量、叶柄长、主 枝基角、种子质量、小枝粗度的变异系数次之, 在 19.36\%-28.68\%之间; 其他 11 个指标变异系数较小, 在9.40\%-16.51\%之间。由此可见, 东北杏定量描述 性状指标变异较大, 体现出较高的遗传多样性。

\section{2 东北杏种质资源定量描述性状的地理变化}

\subsection{1 调查区域地理位置与气候因子的相关性}

15 个调查区域的经度、纬度及海拔与气候因子 (气候指标为1981-2010年的平均值, 数据来自中国 气象数据网 data.cma.cn)的相关性分析(表5)总结如 下: 经度与年均气温、7月平均最高气温、1月平均 最低气温及平均年降水量均呈负相关关系, 其中与 年平均气温、7月平均最低气温及平均年降水量的相
关性达极显著水平 $(p<0.01)$, 与 1 月平均最高气温 的相关性达显著水平 $(p<0.05)$; 纬度与年平均气 温、1月平均最低气温及平均年降水量均呈极显著负 相关关系 $(p<0.01)$; 海拔与年均气温、7月平均最高 气温、1月平均最低气温及平均年降水量均呈负相关 关系，其中与年平均气温、1月平均最高气温的相关 性达显著水平 $(p<0.05)$, 与7月平均最高气温的相 关性达极显著水平 $(p<0.01)$ 。

\subsection{2 定量描述性状与地理位置的相关性}

对47份供试东北杏种质地理分布的纬度、经度 及海拔与定量描述性状指标(树高、胸径和冠幅 3 个 指标受树龄影响较大, 故未参与相关分析)进行相 关性分析(表6), 结果表明: 19个定量描述性状中,

表5 调查区域地理位置与气候因子的相关性

Table 5 Correlation between geographic locations and climatic factors within the study area

\begin{tabular}{|c|c|c|c|c|c|c|c|c|}
\hline \multirow{2}{*}{$\begin{array}{l}\text { 指标 } \\
\text { Index }\end{array}$} & \multicolumn{2}{|c|}{ 年均气温 $\mathrm{AAT}\left({ }^{\circ} \mathrm{C}\right)$} & \multicolumn{2}{|c|}{ 7月平均最高气温 $\mathrm{JAMT}^{1}\left({ }^{\circ} \mathrm{C}\right)$} & \multicolumn{2}{|c|}{ 1月平均最低气温 $\mathrm{JAMT}^{2}\left({ }^{\circ} \mathrm{C}\right)$} & \multicolumn{2}{|c|}{ 年降水量 $\mathrm{AAP}(\mathrm{mm})$} \\
\hline & $\begin{array}{c}\text { 相关系数 } \\
R\end{array}$ & $\begin{array}{c}\text { 显著性 } \\
p\end{array}$ & $\begin{array}{c}\text { 相关系数 } \\
R\end{array}$ & $\begin{array}{c}\text { 显著性 } \\
p\end{array}$ & $\begin{array}{c}\text { 相关系数 } \\
R \\
R\end{array}$ & $\begin{array}{c}\text { 显著性 } \\
p\end{array}$ & $\begin{array}{c}\text { 相关系数 } \\
R\end{array}$ & $\begin{array}{c}\text { 显著性 } \\
p\end{array}$ \\
\hline 经度 Longitude & $-0.810^{* *}$ & $<0.001$ & $-0.649^{* *}$ & 0.009 & $-0.589^{*}$ & 0.021 & $-0.693^{* *}$ & 0.004 \\
\hline 纬度 Latitude & $-0.785^{* *}$ & 0.001 & -0.322 & 0.242 & $-0.656^{* *}$ & 0.008 & $-0.864^{* *}$ & $<0.001$ \\
\hline 海拔 Altitude & $-0.633^{*}$ & 0.011 & $-0.778^{* *}$ & 0.001 & $-0.529^{*}$ & 0.043 & -0.132 & 0.639 \\
\hline
\end{tabular}

AAP, average annual precipitation; AAT, annual average temperature; JAMT ${ }^{1}$, July average maximum temperature; JAMT ${ }^{2}$, January average minimum temperature. ${ }^{*}, p<0.05 ; * *, p<0.01$.

表6 东北杏种质定量描述性状与地理位置的相关性

Table 6 Correlation between the quantitative traits and geographic locations of Armeniaca mandshurica germplasms

\begin{tabular}{|c|c|c|c|c|c|c|}
\hline $\begin{array}{l}\text { 性状 } \\
\text { Traits }\end{array}$ & $\begin{array}{c}\text { 经度 } \\
\text { Longitude (E) }\end{array}$ & $p$ & $\begin{array}{c}\text { 纬度 } \\
\text { Latitude (N) }\end{array}$ & $p$ & $\begin{array}{c}\text { 海拔 } \\
\text { Altitude (m) }\end{array}$ & $p$ \\
\hline 主枝基角 Main branch base angle & 0.277 & 0.060 & $0.351^{*}$ & 0.016 & 0.043 & 0.774 \\
\hline 小枝长度 Twig length & $-0.307^{*}$ & 0.036 & $-0.370^{*}$ & 0.011 & $0.289^{*}$ & 0.049 \\
\hline 小枝粗度 Twig width & $-0.330^{*}$ & 0.023 & $-0.341^{*}$ & 0.019 & -0.274 & 0.062 \\
\hline 叶长 Leaf length & 0.121 & 0.417 & 0.081 & 0.589 & 0.100 & 0.502 \\
\hline 叶宽 Leaf width & $-0.305^{*}$ & 0.037 & -0.226 & 0.127 & -0.109 & 0.466 \\
\hline 叶柄长 Petiole length & -0.088 & 0.555 & -0.138 & 0.354 & 0.176 & 0.236 \\
\hline 单果质量 Single fruit mass & -0.181 & 0.222 & 0.130 & 0.383 & -0.214 & 0.149 \\
\hline 果长 Fruit length & 0.053 & 0.721 & 0.264 & 0.073 & -0.111 & 0.459 \\
\hline 果宽 Fruit width & -0.243 & 0.100 & 0.036 & 0.810 & -0.238 & 0.106 \\
\hline 果厚 Fruit thickness & -0.167 & 0.261 & 0.144 & 0.336 & -0.254 & 0.085 \\
\hline 种子质量 Seed mass & $-0.348^{*}$ & 0.016 & $-0.447^{* *}$ & 0.002 & -0.013 & 0.929 \\
\hline 种子长 Seed length & 0.163 & 0.273 & 0.080 & 0.594 & 0.200 & 0.177 \\
\hline 种子宽 Seed width & -0.195 & 0.190 & -0.188 & 0.205 & 0.084 & 0.576 \\
\hline 种子厚 Seed thickness & -0.106 & 0.479 & -0.073 & 0.625 & 0.167 & 0.261 \\
\hline 种仁质量 Kernel mass & -0.080 & 0.592 & 0.037 & 0.805 & -0.163 & 0.273 \\
\hline 种仁长 Kernel length & 0.043 & 0.776 & -0.073 & 0.625 & 0.067 & 0.656 \\
\hline 种仁宽 Kernel width & -0.146 & 0.327 & -0.099 & 0.510 & -0.178 & 0.232 \\
\hline 种仁厚 Kernel thickness & -0.019 & 0.900 & 0.102 & 0.495 & 0.053 & 0.721 \\
\hline 果柄长 Fruit handle length & $-0.434^{* *}$ & 0.002 & $-0.539^{* *}$ & $<0.001$ & 0.234 & 0.114 \\
\hline
\end{tabular}

*与**分别表示在 $p<0.05$ 和 $p<0.01$ 的显著水平。

$*$ and $* *$ indicate significant correlation at $p<0.05$ and $p<0.01$, respectively.

www.plant-ecology.com 
主枝基角与纬度呈显著正相关关系 $(p<0.05)$; 小枝 长度与经度、纬度显著负相关 $(p<0.05)$, 而与海拔 显著正相关 $(p<0.05)$; 小枝粗度与经度、纬度的相 关性均为显著负相关 $(p<0.05)$; 种子质量与经度呈 显著负相关关系 $(p<0.05)$, 与纬度极显著负相关 $(p$ $<0.01)$; 果柄长与经度、纬度均呈极显著负相关关 系 $(p<0.01)$; 叶宽与经度显著负相关 $(p<0.05)$ 。其 他指标与经度、纬度及海拔没有表现出显著的相关 性 $(p>0.05)$ 。

\subsection{3 定量描述性状与种质产地经度、纬度及海拔 的多项式回归分析}

上述分析表明, 主枝基角、小枝长度、小枝粗 度、叶宽、种子质量和果柄长与种质所处地理位置 显著相关, 采用 $\mathrm{R}$ 软件分别将这些指标与经度、纬度 及海拔进行多项式线性回归分析(表7)。由表7可知, 小枝长度、小枝粗度、种子质量、果柄长的拟合系
数较高且均达到了显著水平 $(p<0.05)$, 可以揭示其 地理变化规律; 而主枝基角和果长的拟合度不够, 不能揭示其地理变化规律。通过表中 $p$ 值大小可知: 海拔对小枝长度和果柄长的影响达显著水平 $(p<$ $0.05)$; 纬度、经度和海拔对小枝粗度、种子质量的 影响均未达显著水平 $(p>0.05)$ 。

将供试种质所处的海拔平均值代入小枝长度、 小枝粗度、种子质量和果柄长的回归方程中(廖柏勇 等, 2016), 采用Surfer 12.0软件分别做经、纬度趋势 面图(图1)。由图可知：小枝长度呈由东向西逐渐增 加的梯度变化, 小枝粗度呈由北到南逐渐增加的梯 度变化, 种子质量呈由北到南逐渐增加的梯度变化, 果柄长呈由东北到西南逐渐增加的梯度变化。

再将平均经度和平均纬度代入回归方程, 采用 Excel 2010分别做海拔趋势曲线图(图2)。由图2可知: 小枝长度、果柄长与海拔呈正相关关系, 随海拔升

表7 东北杏种质定量描述性状与地理位置多项式回归分析

Table 7 Polynomial regression analysis of the quantitative traits and geographic locations of Armeniaca mandshurica germplasms

\begin{tabular}{|c|c|c|c|c|c|c|}
\hline $\begin{array}{l}\text { 性状 } \\
\text { Traits }\end{array}$ & $\begin{array}{l}\text { 多项式变量 } \\
\text { Polynomial variable }\end{array}$ & $\begin{array}{l}\text { 分项系数 } \\
\text { Coefficient }\end{array}$ & $\begin{array}{c}\text { 标准误差 } \\
\text { Standard Error }\end{array}$ & $\begin{array}{c}\text { 系数显著性 } \\
p \text { of coefficient }\end{array}$ & $\begin{array}{l}\text { 方程显著性 } \\
p \text { of equation }\end{array}$ & $\begin{array}{c}\text { 拟合系数 } \\
C\end{array}$ \\
\hline \multirow[t]{4}{*}{$\begin{array}{l}\text { 主枝基角 } \\
\text { Main branch base angle }\end{array}$} & $\begin{array}{l}\text { 常数项 Constant } \\
\text { term }\end{array}$ & -24.139 & 81.028 & 0.767 & \multirow[t]{4}{*}{0.123} & \multirow[t]{4}{*}{0.124} \\
\hline & 纬度 Latitude & 1.746 & 1.186 & 0.148 & & \\
\hline & 经度 Longitude & -0.143 & 0.950 & 0.881 & & \\
\hline & 海拔 Altitude & 0.002 & 0.009 & 0.808 & & \\
\hline \multirow[t]{4}{*}{$\begin{array}{l}\text { 小枝长度 } \\
\text { Twig length }\end{array}$} & $\begin{array}{l}\text { 常数项 Constant } \\
\text { term }\end{array}$ & 949.078 & 349.745 & 0.010 & \multirow[t]{4}{*}{0.003} & \multirow[t]{4}{*}{0.278} \\
\hline & 纬度 Latitude & -1.059 & 5.121 & 0.837 & & \\
\hline & 经度 Longitude & -6.967 & 4.099 & 0.096 & & \\
\hline & 海拔 Altitude & 0.115 & 0.040 & 0.006 & & \\
\hline \multirow[t]{4}{*}{$\begin{array}{l}\text { 小枝粗度 } \\
\text { Twig width }\end{array}$} & $\begin{array}{l}\text { 常数项 Constant } \\
\text { term }\end{array}$ & 5.605 & 6.419 & 0.387 & \multirow[t]{4}{*}{0.030} & \multirow[t]{4}{*}{0.186} \\
\hline & 纬度 Latitude & -0.151 & 0.094 & 0.115 & & \\
\hline & 经度 Longitude & 0.026 & 0.075 & 0.728 & & \\
\hline & 海拔 Altitude & -0.001 & 0.001 & 0.082 & & \\
\hline \multirow[t]{4}{*}{$\begin{array}{l}\text { 叶宽 } \\
\text { Leaf width }\end{array}$} & $\begin{array}{l}\text { 常数项 Constant } \\
\text { term }\end{array}$ & 210.474 & 85.886 & 0.018 & \multirow[t]{4}{*}{0.232} & \multirow[t]{4}{*}{0.094} \\
\hline & 纬度 Latitude & 0.261 & 1.257 & 0.836 & & \\
\hline & 经度 Longitude & -1.261 & 1.007 & 0.217 & & \\
\hline & 海拔 Altitude & 0.001 & 0.010 & 0.925 & & \\
\hline \multirow[t]{4}{*}{$\begin{array}{l}\text { 种子质量 } \\
\text { Seed mass }\end{array}$} & $\begin{array}{l}\text { 常数项 Constant } \\
\text { term }\end{array}$ & 3.809 & 2.608 & 0.151 & \multirow[t]{4}{*}{0.021} & \multirow[t]{4}{*}{0.200} \\
\hline & 纬度 Latitude & -0.071 & 0.038 & 0.070 & & \\
\hline & 经度 Longitude & 0.002 & 0.031 & 0.950 & & \\
\hline & 海拔 Altitude & $1.853 \times 10^{-6}$ & $<0.001$ & 0.995 & & \\
\hline \multirow[t]{4}{*}{$\begin{array}{l}\text { 果柄长 } \\
\text { Fruit handle length }\end{array}$} & $\begin{array}{l}\text { 常数项 Constant } \\
\text { term }\end{array}$ & 87.172 & 27.568 & 0.003 & \multirow[t]{4}{*}{$<0.001$} & \multirow[t]{4}{*}{0.388} \\
\hline & 纬度 Latitude & -0.528 & 0.404 & 0.198 & & \\
\hline & 经度 Longitude & -0.475 & 0.323 & 0.149 & & \\
\hline & 海拔 Altitude & 0.008 & 0.003 & 0.012 & & \\
\hline
\end{tabular}



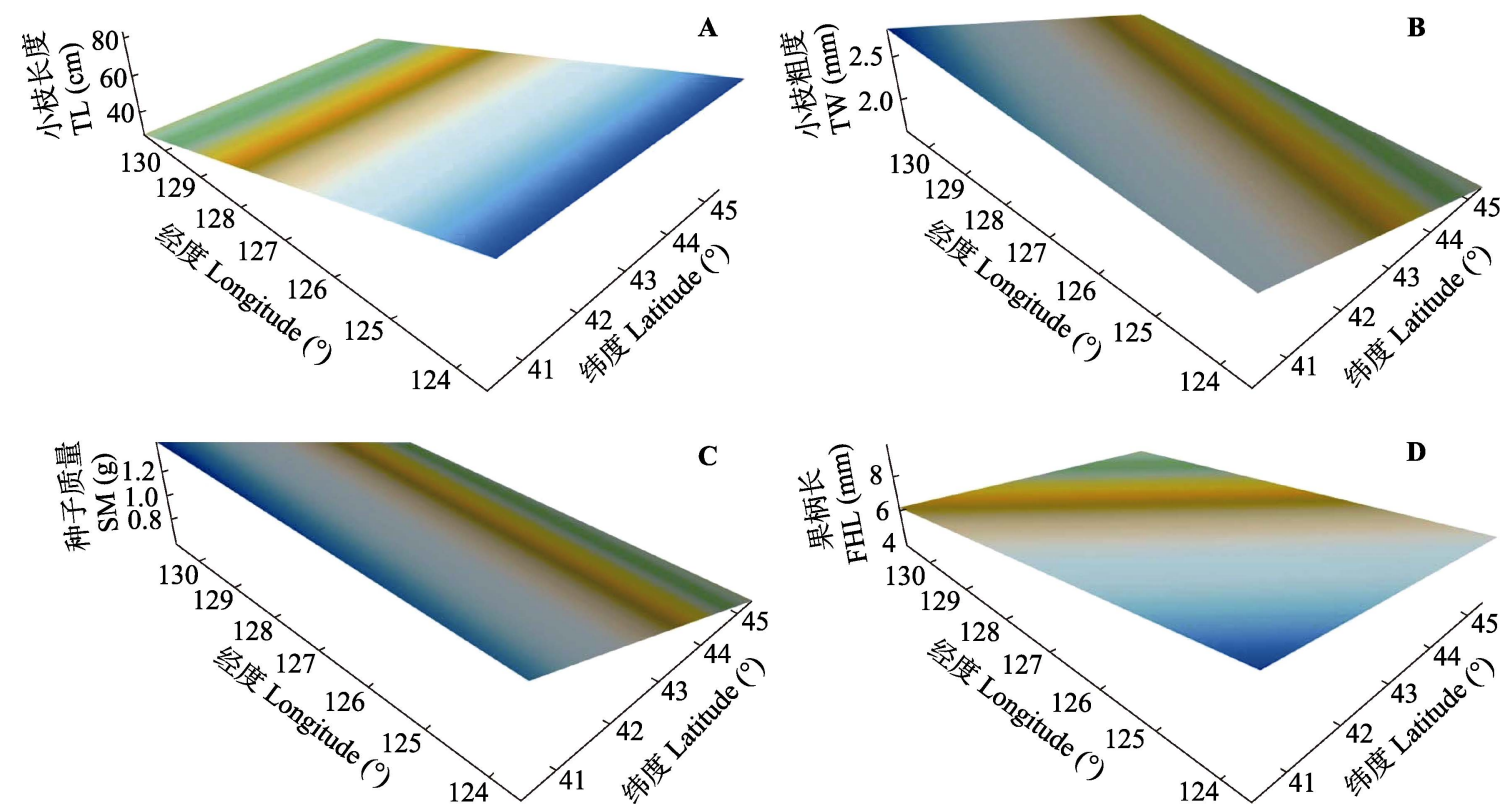

图1 东北杏种质定量描述性状与经纬度趋势面图。 $\mathbf{A}$, 小枝长度。 $\mathbf{B}$, 小枝粗度。 $\mathbf{C}$, 种子质量。 $\mathbf{D}$, 果柄长。

Fig. 1 Trend surface analyses between the quantitative traits and the geographical coordinates (i.e. latitude and longitude) of Armeniaca mandshurica germplasms. A, Trend surface map between twig length (TL), latitude and longitude. B, Trend surface map between twig width (TW), latitude and longitude. C, Trend surface map between seed mass (SM), latitude and longitude. D, Trend surface map between fruit handle length (FHL), latitude and longitude.
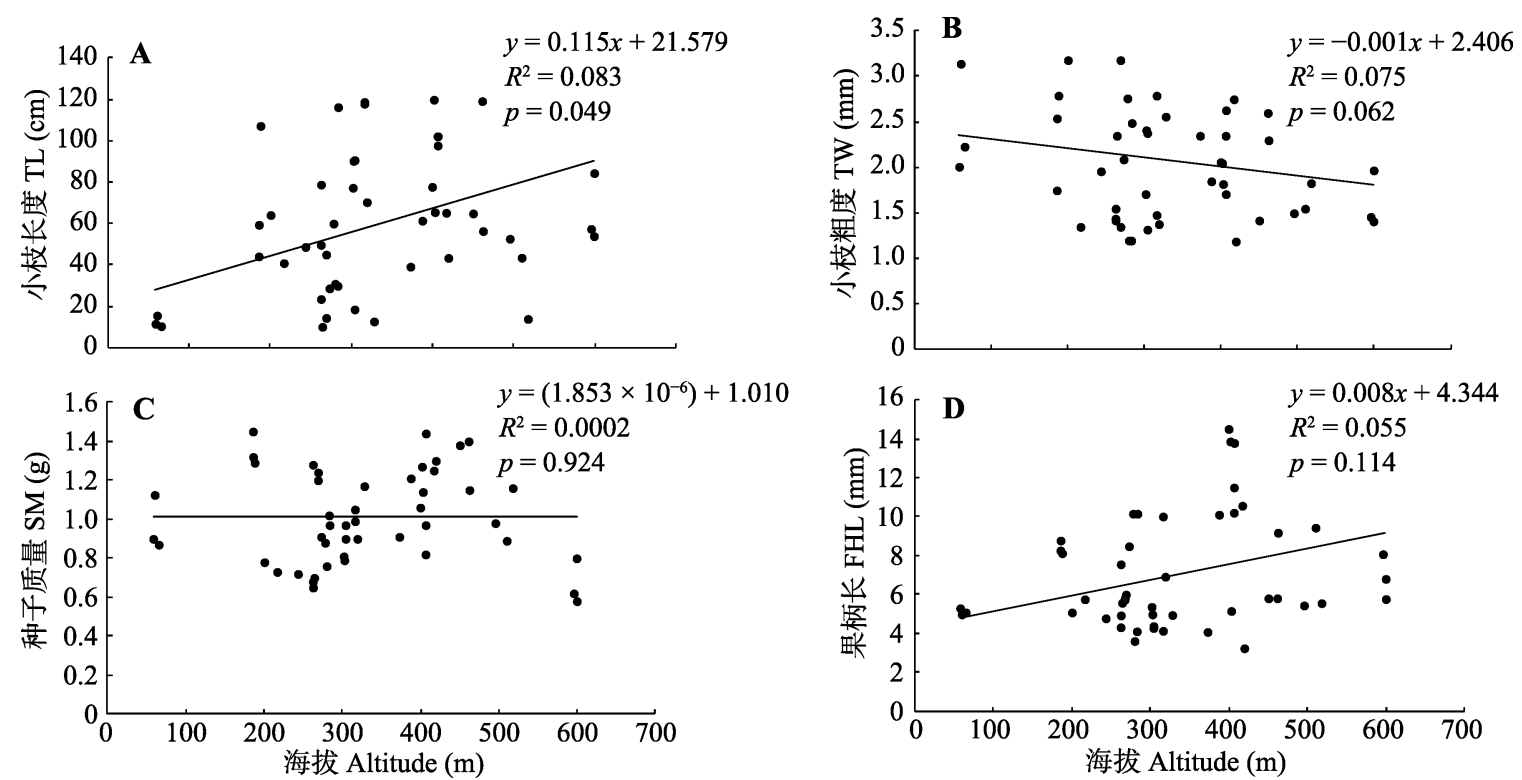

图2 东北杏种质定量描述性状与海拔趋势曲线图。 $\mathbf{A}$, 小枝长度。 $\mathbf{B}$, 小枝粗度。 $\mathbf{C}$, 种子质量。 $\mathbf{D}$, 果柄长。

Fig. 2 Relationships between quantitative traits and altitude of Armeniaca mandshurica germplasms. A, Trend curve between twig length (TL) and altitude. B, Trend curve between twig width (TW) and altitude. C, Trend curve between seed mass (SM) and altitude. D, Trend curve between fruit handle length (FHL) and altitude.

高而增加; 小枝粗度与海拔呈负相关关系，随海拔 升高而减小; 种子质量与海拔相关性很小。

\section{3 基于表型性状的东北杏种质分类}

本文根据19个定量描述性状和7个定性描述性 状对47份东北杏种质进行主成分分析，按照特征值 大于 1 进行抽取 (因树高、胸径和冠幅 3 个指标受树龄
影响较大, 故未参与主成分分析)。表8列出了各个 指标对应的方差分量(载荷值的平方)及各主成分对 应的特征根和贡献率。

由表 8 可知, 前 10 个主成分累计贡献率为 $76.113 \%$ 。第一主成分中单果质量、果长、果宽、 果厚、种子质量、种子长、种子宽、种子厚、种仁 
质量、种仁长、种仁宽的方差分量较大，可看作是 反映果、核、仁大小的综合指标。第二主成分中叶 基形状、叶缘形状的方差分量较大，可作为叶片形 态特征的综合指标。第三主成分中主枝基角、小枝 长度、叶长具有较大的方差分量, 即第三主成分主 要代表了树体特征。第四主成分中小枝粗度、腺体 数量具有较大的方差分量。第五主成分中果柄长的 方差分量较大。第七主成分中果实形状具有较大的 方差分量。第九主成分中叶宽的方差分量较大。其 余主成分指示作用不明显。

基于 47 份东北杏种质的主成分得分值，运用 Ward法进行系统聚类, 结果如图3所示。
在横坐标 12.5 处划线, 将种质划分为四类(分别 用 $A 、 B 、 C 、 D$ 表示)。表 9 为各类主要定量描述性 状。

$\mathrm{A}$ 类包括 23 份种质，该类总体特征为主枝基角 小，小枝长且粗; 果柄长，果大小中等，种子大，种 仁较大; 叶柄长, 叶片大小中等。叶基均为宽楔形, 大部分种质小枝为绿色(701和708号种质除外)。种 质产地以调查区域的南部为主，其中14份种质位于 辽宁东部地区(704、705、702、703、713、701、706、 712、710、711、708、709、707、724), 5份种质位 于吉林东部地区(746、742、741、749、758), 4份种 质位于黑龙江东部地区(774、777、778、779)。

表8 东北杏种质表型性状的主成分分析

Table 8 Principal component analysis on the phenotypic traits of Armeniaca mandshurica germplasms

\begin{tabular}{|c|c|c|c|c|c|c|c|c|c|c|}
\hline \multirow{2}{*}{$\begin{array}{l}\text { 性状 } \\
\text { Traits }\end{array}$} & \multicolumn{10}{|c|}{ 主成分 Principal component } \\
\hline & $\mathrm{PC} 1$ & $\mathrm{PC} 2$ & $\mathrm{PC} 3$ & $\mathrm{PC} 4$ & PC5 & PC6 & PC7 & PC8 & PC9 & $\mathrm{PC} 10$ \\
\hline 主枝基角 Main branch base angle & 0.005 & 0.009 & 0.282 & 0.008 & 0.097 & 0.007 & 0.091 & 0.239 & 0.009 & 0.015 \\
\hline 小枝长度 Twig length & 0.001 & 0.002 & 0.450 & 0.000 & 0.174 & 0.027 & 0.019 & 0.076 & 0.052 & 0.001 \\
\hline 小枝粗度 Twig width & 0.008 & 0.004 & 0.004 & 0.290 & 0.144 & 0.064 & 0.120 & 0.003 & 0.004 & 0.005 \\
\hline 叶长 Leaf length & 0.000 & 0.049 & 0.337 & 0.282 & 0.012 & 0.019 & 0.041 & 0.004 & 0.061 & 0.006 \\
\hline 叶宽 Leaf width & 0.000 & 0.011 & 0.108 & 0.120 & 0.074 & 0.019 & 0.093 & 0.003 & 0.407 & 0.000 \\
\hline 叶柄长 Petiole length & 0.006 & 0.216 & 0.112 & 0.068 & 0.008 & 0.164 & 0.002 & 0.007 & 0.021 & 0.056 \\
\hline 单果质量 Single fruit mass & 0.591 & 0.139 & 0.001 & 0.004 & 0.009 & 0.009 & 0.007 & 0.001 & 0.003 & 0.019 \\
\hline 果长 Fruit length & 0.659 & 0.006 & 0.053 & 0.023 & 0.000 & 0.141 & 0.003 & 0.008 & 0.011 & 0.002 \\
\hline 果宽 Fruit width & 0.648 & 0.129 & 0.022 & 0.006 & 0.039 & 0.000 & 0.026 & 0.004 & 0.000 & 0.006 \\
\hline 果厚 Fruit thickness & 0.665 & 0.184 & 0.020 & 0.011 & 0.028 & 0.001 & 0.001 & 0.032 & 0.001 & 0.000 \\
\hline 种子质量 Seed mass & 0.455 & 0.192 & 0.074 & 0.036 & 0.006 & 0.002 & 0.008 & 0.001 & 0.006 & 0.003 \\
\hline 种子长 Seed length & 0.337 & 0.283 & 0.010 & 0.047 & 0.058 & 0.097 & 0.000 & 0.075 & 0.001 & 0.031 \\
\hline 种子宽 Seed width & 0.476 & 0.145 & 0.009 & 0.014 & 0.006 & 0.094 & 0.050 & 0.039 & 0.020 & 0.001 \\
\hline 种子厚 Seed thickness & 0.449 & 0.096 & 0.002 & 0.012 & 0.049 & 0.172 & 0.004 & 0.046 & 0.001 & 0.020 \\
\hline 种仁质量 Kernel mass & 0.461 & 0.005 & 0.104 & 0.084 & 0.040 & 0.014 & 0.026 & 0.029 & 0.008 & 0.000 \\
\hline 种仁长 Kernel length & 0.334 & 0.178 & 0.032 & 0.016 & 0.033 & 0.180 & 0.001 & 0.015 & 0.000 & 0.035 \\
\hline 种仁宽 Kernel width & 0.319 & 0.046 & 0.058 & 0.153 & 0.105 & 0.064 & 0.008 & 0.038 & 0.006 & 0.020 \\
\hline 种仁厚 Kernel thickness & 0.066 & 0.023 & 0.186 & 0.047 & 0.085 & 0.130 & 0.116 & 0.000 & 0.023 & 0.072 \\
\hline 果柄长 Fruit handle length & 0.016 & 0.033 & 0.112 & 0.052 & 0.377 & 0.043 & 0.037 & 0.014 & 0.016 & 0.015 \\
\hline 小枝色泽 Twig color & 0.227 & 0.205 & 0.090 & 0.023 & 0.134 & 0.139 & 0.149 & 0.159 & 0.016 & 0.168 \\
\hline 叶背被毛 Leaf back fuzzed & 0.014 & 0.056 & 0.016 & 0.116 & 0.069 & 0.028 & 0.186 & 0.006 & 0.099 & 0.146 \\
\hline 叶表被毛 Leaf surface fuzzed & 0.000 & 0.212 & 0.155 & 0.177 & 0.041 & 0.051 & 0.007 & 0.047 & 0.054 & 0.000 \\
\hline 叶基形状 Leaf base shape & 0.030 & 0.273 & 0.017 & 0.205 & 0.238 & 0.250 & 0.304 & 0.156 & 0.069 & 0.044 \\
\hline 叶缘形状 Leaf edge shape & 0.001 & 0.262 & 0.214 & 0.122 & 0.002 & 0.001 & 0.019 & 0.088 & 0.049 & 0.010 \\
\hline 腺体数量 Number of glands & 0.068 & 0.230 & 0.037 & 0.263 & 0.098 & 0.021 & 0.098 & 0.129 & 0.137 & 0.055 \\
\hline 果实形状 Fruit shape & 0.210 & 0.388 & 0.141 & 0.163 & 0.317 & 0.345 & 0.424 & 0.151 & 0.205 & 0.398 \\
\hline 特征根 Eigenvalue & 6.047 & 3.376 & 2.644 & 2.345 & 2.244 & 2.083 & 1.841 & 1.369 & 1.280 & 1.127 \\
\hline 贡献率(\%) Contribution rate & 18.896 & 10.549 & 8.261 & 7.329 & 7.013 & 6.510 & 5.754 & 4.279 & 4.001 & 3.521 \\
\hline $\begin{array}{l}\text { 累积贡献率 }(\%) \\
\text { Cumulative contribution rate }\end{array}$ & 18.896 & 29.445 & 37.706 & 45.035 & 52.048 & 58.558 & 64.312 & 68.591 & 72.592 & 76.113 \\
\hline
\end{tabular}




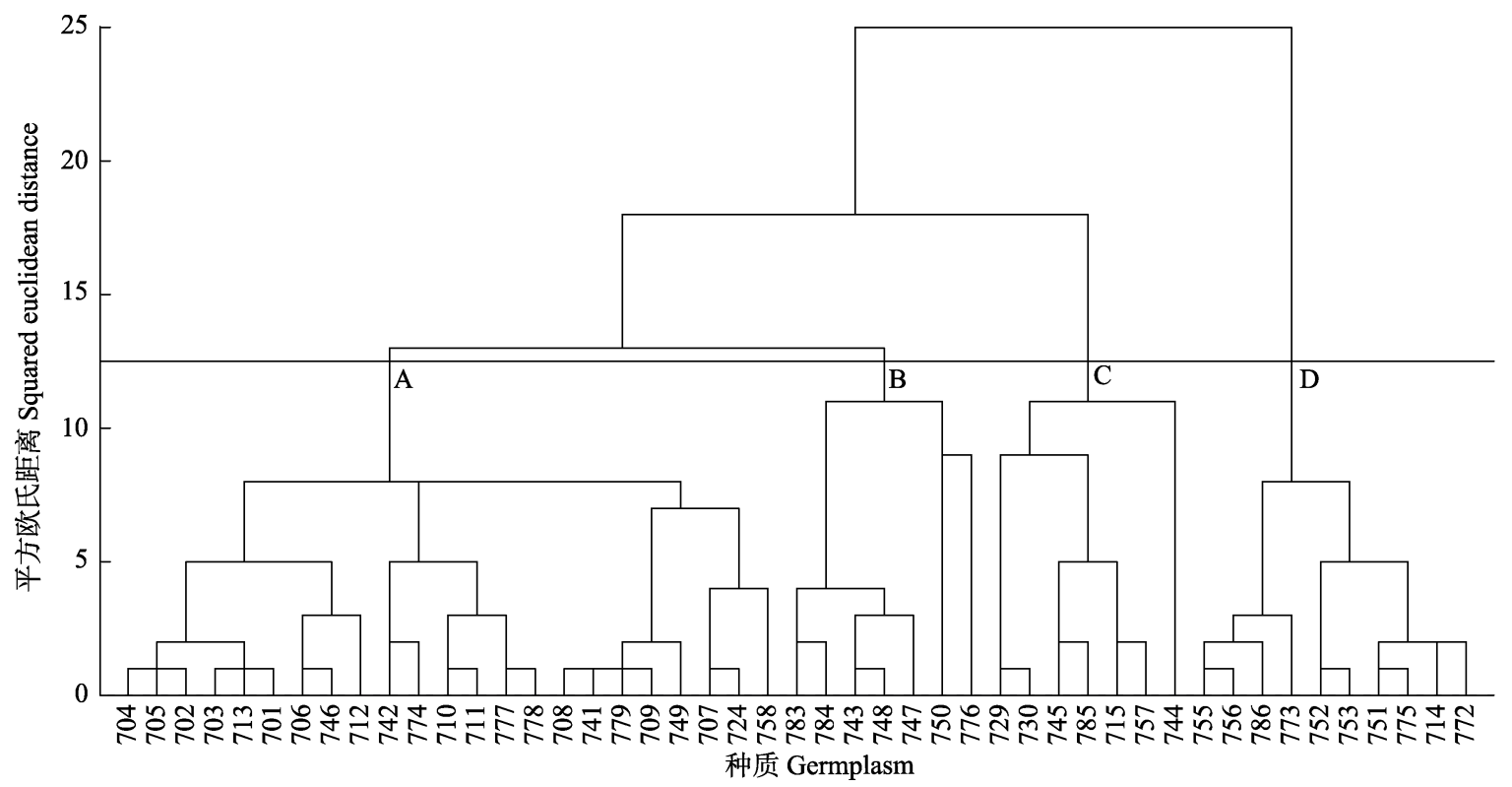

图3 基于表型性状的东北杏种质聚类结果。

Fig. 3 Clustering result of Armeniaca mandshurica germplasms based on phenotypic traits.

表9＼cjkstart东北杏种质各类别主要定量描述性状

Table 9 Statistics of the quantitative traits of Armeniaca mandshurica germplasms in each category

\begin{tabular}{lllllllllll}
\hline $\begin{array}{l}\text { 类别 } \\
\text { Categories }\end{array}$ & $\begin{array}{llllll}\text { 单果质量 } \\
\text { SFM }(\mathrm{g})\end{array}$ & $\begin{array}{l}\text { 种子质量 } \\
\mathrm{SM}(\mathrm{g})\end{array}$ & $\begin{array}{l}\text { 种仁质量 } \\
\mathrm{SM}(\mathrm{g})\end{array}$ & $\begin{array}{l}\text { 小枝长度 } \\
\mathrm{TL}(\mathrm{cm})\end{array}$ & $\begin{array}{l}\text { 小枝粗度 } \\
\mathrm{TW}(\mathrm{mm})\end{array}$ & $\begin{array}{l}\text { 主枝基角 } \\
\text { MBBA }\left({ }^{\circ}\right)\end{array}$ & $\begin{array}{l}\text { 叶长 } \\
\text { LL }(\mathrm{mm})\end{array}$ & $\begin{array}{l}\text { 叶宽 } \\
\mathrm{LW}(\mathrm{mm})\end{array}$ & $\begin{array}{l}\text { 叶柄长 } \\
\text { PL }(\mathrm{mm})\end{array}$ & $\begin{array}{l}\text { 果柄长 } \\
\mathrm{FHL}(\mathrm{mm})\end{array}$ \\
\hline $\mathrm{A}$ & 4.35 & 1.11 & 0.30 & 67.80 & 2.25 & 30.61 & 97.92 & 63.25 & 31.58 & 8.02 \\
& $(0.89)$ & $(0.21)$ & $(0.05)$ & $(34.75)$ & $(0.58)$ & $(6.37)$ & $(9.43)$ & $(7.02)$ & $(6.75)$ & $(3.15)$ \\
$\mathrm{B}$ & 5.27 & 1.04 & 0.28 & 36.80 & 1.98 & 39.86 & 101.79 & 63.80 & 31.09 & 5.23 \\
& $(1.84)$ & $(0.26)$ & $(0.42)$ & $(22.20)$ & $(0.66)$ & $(6.47)$ & $(13.00)$ & $(4.65)$ & $(6.20)$ & $(0.56)$ \\
$\mathrm{C}$ & 6.01 & 1.03 & 0.32 & 57.00 & 1.76 & 35.57 & 97.22 & 60.10 & 27.01 & 7.43 \\
& $(1.95)$ & $(0.15)$ & $(0.40)$ & $(42.44)$ & $(0.36)$ & $(7.91)$ & $(12.64)$ & $(7.68)$ & $(5.61)$ & $(6.38)$ \\
$\mathrm{D}$ & 2.99 & 0.73 & 0.24 & 59.55 & 1.68 & 34.70 & 96.45 & 60.91 & 28.87 & 5.78 \\
& $(0.81)$ & $(0.10)$ & $(0.06)$ & $(25.85)$ & $(0.43)$ & $(5.19)$ & $(13.82)$ & $(9.54)$ & $(4.77)$ & $(1.24)$ \\
群体平均值 & 4.65 & 0.98 & 0.29 & 55.29 & 1.92 & 35.18 & 98.35 & 62.02 & 29.64 & 6.61 \\
$\begin{array}{l}\text { Average value } \\
\text { of population }\end{array}$ & $(1.30)$ & $(0.17)$ & $(0.03)$ & $(13.15)$ & $(0.26)$ & $(3.79)$ & $(2.37)$ & $(1.79)$ & $(2.11)$ & $(1.32)$ \\
\hline
\end{tabular}

\section{括号中为标准偏差。}

The number in parentheses is standard deviation. FHL, fruit handle length; KM, kernel mass; LL, leaf length; LW, leaf width; MBBA, main branch base angle; PL, petiole length; SFM, single fruit mass; SM, seed mass; TL, twig length; TW, twig width.

B类包括7份种质，该类总体特征为主枝基角大， 小枝短、较粗; 叶柄长, 叶片大; 果柄短, 果较大, 种子、种仁大小中等。叶背均被毛, 大部分种质叶 缘为锐重锯齿(783号种质除外)。种质产地为调查区 域的中部和北部, 其中4份种质位于吉林东部地区 (743、748、747、750), 3份种质位于黑龙江东部地 区(783、784、776)。

C类包括7份种质，该类总体特征为主枝基角中 等, 小枝细、长度中等; 叶柄短, 叶片小; 果柄较长, 果大, 种仁大, 种子大小中等; 多数种质叶缘为钝 重锯齿且叶柄具 2 个腺体(785 号种质除外)。种质产 地以调查区域的中部和南部为主, 其中 3 份种质位 于辽宁东部地区(729、730、715), 3份种质位于吉林
东部地区(745、757、744), 1份种质位于黑龙江东部 地区(785)。

$\mathrm{D}$ 类包括 10 份种质，该类总体特征为主枝基角 中等, 小枝细、较长; 叶柄长度中等, 叶片小; 果柄 短, 果、种子、种仁小。所有种质小枝均为绿色。 种质产地以调查区域的中部和北部为主, 其中 3 份 种质位于黑龙江东部地区(786、773、775), 5份种质 位于吉林东部地区(755、756、752、753、751), 1份 种质位于辽宁东部地区(714)。

上述分类结果主要体现了东北杏种质特征的差 异，在一定程度上也体现了种质产地的效应。

\section{4 表型聚类和SSR分子标记聚类的相关分析}

根据沈阳农业大学山杏课题组2014年进行的山 
杏简化基因组测序结果，由北京赛百盛基因技术有 限公司合成600对SSR引物, 从中篮选出99对扩增 条带清晰、多态性高的引物, 对47份东北杏种质的 基因组DNA进行扩增, 平均每个位点的等位基因数 为 8.879 个, 多态性信息含量为 0.718 (各位点信息详 见附录 I )。基于 99 个SSR 位点数据, 分析 47 份东北 杏种质间的遗传相似性, 结果表明, 遗传相似系数 在0.726-0.934之间, 平均为 0.797 , 遗传差异较小, 亲缘关系较近。以遗传相似系数为基础, 采用 UPGMA法进行聚类分析, 在相似系数 0.83 处可以 分为 4 大类(图4)。

第1大类包括 15 份种质 $(701 、 702 、 703 、 704 、$ 705、706、707、708、709、710、711、712、713、
714、715), 均来自于辽宁东部地区，即调查区域的 东南部; 第2大类包括3份种质(724、729、730), 均 来自于辽宁沈阳市，即调查区域的西南部; 第3大 类包括17份种质(741、742、743、744、745、746、 747、748、749、750、751、752、753、755、756、 757、758)，均来自于吉林东部地区，即调查区域的 中部; 第4大类包括12份种质(772、773、774、775、 776、777、778、779、783、784、785、786), 均来 自于黑龙江东部地区，即调查区域的北部。聚类结 果反映了种质产地的效应。

为了探讨表型聚类与 SSR 分子标记聚类结果的 关系, 进行卡方检验(表10), 结果表明, 两种聚类结 果的相关性未达到显著水平 $(p>0.05)$ 。

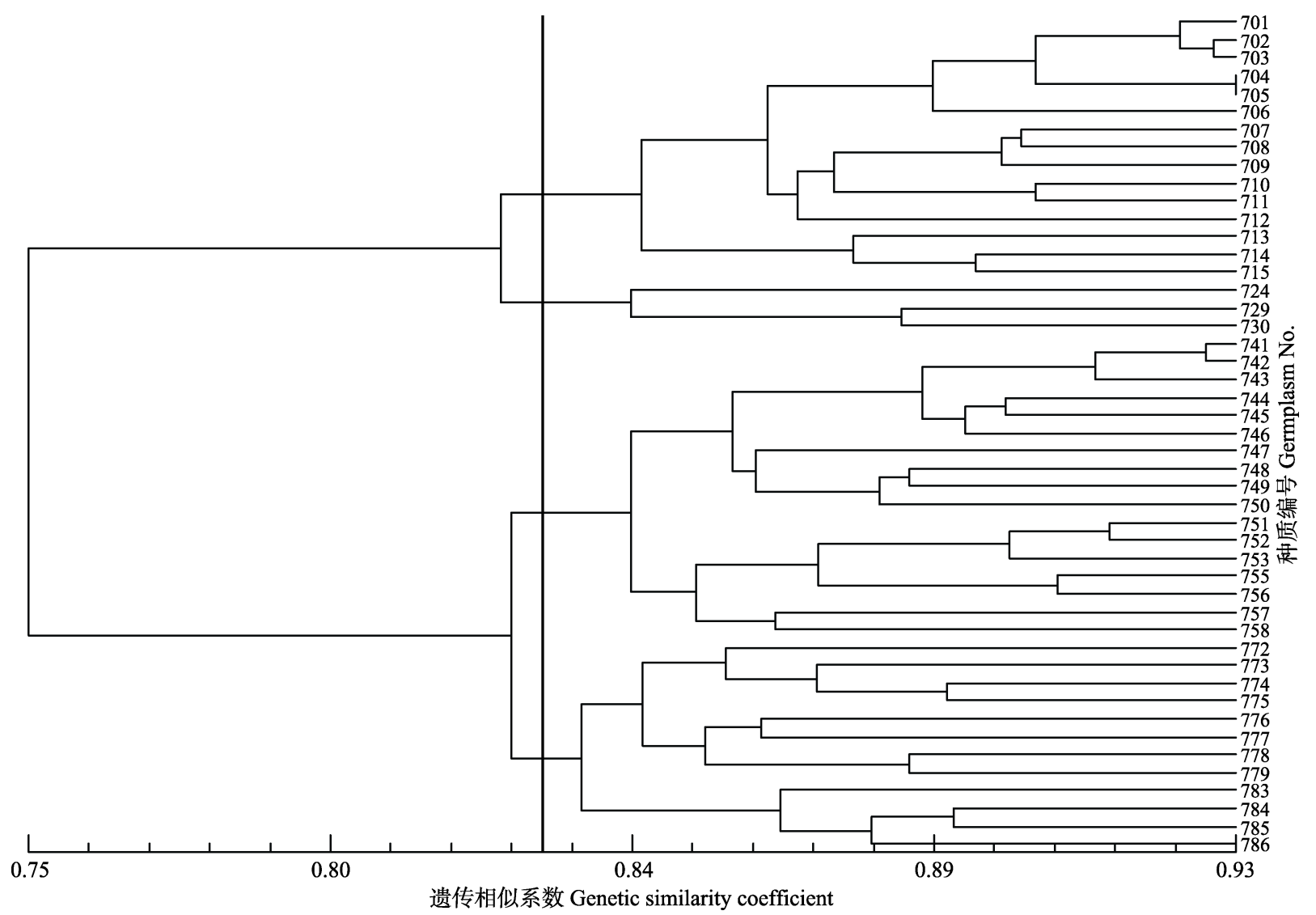

图4 基于SSR分子标记的东北杏种质聚类结果。种质编号同表1。

Fig. 4 Clustering result of Armeniaca mandshurica germplasms based on SSR molecular markers. Germplasm No. see Table 1.

表10 东北杏种质基于表型性状和SSR分子标记聚类结果间的相关性

Table 10 Relationship between clustering results based on phenotypic traits and SSR molecular markers of Armeniaca mandshurica germplasms

\begin{tabular}{lcccccc}
\hline 表型性状聚类 & \multicolumn{2}{c}{ SSR分子标记聚类 } & \multicolumn{2}{c}{ Clustering based on SSR molecular markers } & & \multirow{2}{*}{$\chi^{2}$} \\
\cline { 2 - 5 } Clustering based on phenotypic traits & 1 & 2 & 3 & & \\
\hline 1 & 13 & 1 & 5 & 4 & $3.250^{\mathrm{a}}$ & 0.777 \\
2 & 0 & 0 & 4 & 3 & \\
3 & 1 & 2 & 3 & 1 & \\
4 & 1 & 0 & 5 & 3 & \\
\hline
\end{tabular}




\section{3 讨论}

\section{1 东北杏种质表型性状呈现出遗传多样性}

遗传参数中变异系数可在一定程度上反映性 状的离散程度, 变异系数越大, 离散程度越高, 多 样性程度越高(柳江群等, 2017), 一般情况下变异系 数大于 $10 \%$, 说明该性状在不同种质间的差异较大, 多样性丰富(白史且等, 2002); Shannon-Wiener多样 性指数是用来描述不同性状出现的紊乱和不确定性, 不确定性越高, 多样性也就越高(孙儒泳, 2002)。本 研究基于 47 份东北杏种质的 26 个表型性状进行统计 分析, 19 个定量描述性状指标的变异系数在 $9.40 \%-$ $55.98 \%$ 之间，7个定性描述性状指标的 ShannonWiener多样性指数在 $0.57-1.22$ 之间, 表现出较高的 遗传多样性。其中小枝长度、果柄长和单果质量的 变异系数较大, 分别为 $55.98 \%$ 、 $40.71 \%$ 和 $34.77 \%$; 种仁质量、叶柄长、主枝基角、种子质量、小枝粗 度的变异系数次之, 在 $19.36 \%-28.68 \%$ 之间。雷鸣雷 等(2012)研究认为, 宁夏彭阳县野杏变异系数较大 的指标为嫩枝长、雌荵发育程度、果质量、节间长 度、出核率、仁质量、核质量, 其大小分别为 $39.8 \%$ 、 $38.4 \% 、 30.2 \% 、 30.1 \% 、 26.2 \% 、 26.2 \%$ 和 $23.9 \%$, 本 研究结果与之基本一致。仲维平等(2015)研究表明, 内蒙古扎兰屯地区山杏(Armeniaca sibirica) 的嫩枝 长、节间长度、叶柄长、完全花比例、嫩枝粗、叶 宽、叶长/叶柄长、核质量的变异系数均超过 $20 \%$, 本 研究结果在小枝性状、叶柄性状及种子大小方面与 之一致。与上述文献不同的是, 本研究中东北杏在 果柄长、主枝基角上也呈现出较大的变异, 这是由 树种生物学特性和研究区域的自然条件特点所决定 的。对19个主要定量描述性状进行 $K-S$ 正态性检验的 结果表明, 除果柄长外的 18 个定量描述性状均符合 正态分布, 说明该树种受人为干扰较少, 主要处于 野生、半野生状态, 与赵海娟等(2013)对普通杏 (Armeniaca vulgaris) 的研究结果类似。

\section{2 东北杏种质定量描述性状的地理变化}

相关性分析结果(表5)表明, 调查区域的地理位 置与主要气候因子之间存在着显著的负相关性, 地 理位置梯度的变化反映了气候条件的变化。因此, 随着经、纬度的升高, 气温降低, 降水减少, 东北杏 种质小枝长度、小枝粗度、种子质量和果柄长呈现 出显著或极显著变小的趋势。在其地理变化中, 小
枝长度表现为由东到西逐渐增大的梯度变化, 经度 是主要影响因子; 小枝粗度、种子质量表现为由北 到南逐渐增大的梯度变化, 纬度是主要影响因子; 果柄长表现为由东北到西南逐渐增大的梯度变化, 经、纬度均是主要影响因子。五角枫(Acer mono) 果 柄长、任豆(Zenia insignis)种子质量的地理变化规律 与东北杏一致(姬志峰, 2013; 林玮等, 2016)。本研究 发现, 叶宽与经度显著负相关, 这是因为随着经度 的升高, 降水减少, 叶片变小不仅可以削弱自身的 边界层阻力, 增加叶片的保水性, 而且可以减缓叶 温升高的速率, 从而提高植物对有限水分的利用效 率(McDonald et al., 2003; 任红剑等, 2018); 而主枝 基角与纬度显著正相关, 这是因为随着纬度的增加, 气温降低, 年日照时间变短, 光谱中短波成分增加, 为了适应这些环境胁迫，植株通过增大主枝基角， 更好地接受太阳光, 提高树冠内的温度, 有利于植 株的光合作用, 促进生长(苏渤海等, 2008; 李军如 和宋涛, 2013)。

随着海拔的升高, 各种气象要素也发生相应变 化, 在一定海拔高度范围内, 海拔升高, 温度降低, 大气压减小, 空气所能容纳的水汽含量降低, 进而 导致大气相对湿度的增加(郑征等, 2007)。本研究表 明，小枝粗度与海拔呈负相关关系，这与经纬度的 作用机理一致。但小枝长度、果柄长与海拔均呈正 相关关系, 其中小枝长度与海拔的相关性达显著水 平, 这与李曼等(2017)的研究结果相似。这是因为在 高海拔处, 水分、温度等胁迫因子加剧, 植物小枝和 果柄不仅需要承担运输水分和养分的功能, 还需要 增加对茎的投入, 以支撑风、雪等因素对茎产生的 压力。恒定胁迫模型理论认为, 令植物茎横截面外 缘弯曲所需要做的功(即弯曲矩) $M$ 主要是由作用于 茎上的力 $(F)$ 和茎的长度 $(L)$ 决定, 即 $M=F \times L$ 。当植 物小枝和果柄面临大风、降雪等压力时, 通过增加 其长度, 进而增大茎基部所能承受的最大弯曲胁迫, 有利于保持茎的稳定性。其次, 通过增加小枝的长 度, 以便将更多叶片伸展到冠层以外, 减少叶片之 间的互相遮蔽, 有利于植物更有效地获取光能, 提 高光合效率(Niklas, 1999; 李俊慧等, 2017)。

地理位置对东北杏种质表型性状影响较大, 所 以在进行良种选育时, 应将野外优选种质定植于相 同条件下, 采取同样的经营措施, 以排除自然条件、 林龄及经营措施所造成的影响, 在此基础上进行形 
态观测，笁选出优良单株。

\section{3 东北杏种质的分类}

通过主成分分析和聚类分析, 基于表型性状和 分子标记均可将 47 份东北杏种质分为 4 类, 但从聚 类结果分析来看, 2 种方法的分类存在较大差异, 在 柚(Citrus maxima)(彭瑜等, 2008)、油橄榄(Olea europaea)(秦倩等, 2016)、牡丹(Paeonia spp.)(翟立娟, 2019)等植物的研究中也存在形态学聚类和分子标 记聚类结果不一致的情况。

本研究调查区域包括辽宁、吉林和黑龙江的 15 个地区, 基本覆盖了东北杏的主要分布区, 调查区 域内年平均气温为 $3.4-8.5{ }^{\circ} \mathrm{C}$, 降水量为 530.2$1077.8 \mathrm{~mm}$, 由于地理隔离和长期的自然选择, 不 同产地的种质形成了相应的遗传特性(金玲等, 2018), 同时东北杏为虫媒传粉植物, 同风媒传粉植 物花粉相比, 其花粉的传播距离受到限制, 导致种 群间的基因流水平相对较低, 增加了种群间分化的 可能性(刀松锋等, 2014), 因此基于SSR分子标记的 东北杏种质聚类结果与种质产地高度吻合。基于表 型性状的聚类结果中既存在地理位置较近的种质聚 为一类的情况, 也存在地理位置较远的种质聚为一 类的情况，表型性状表现为空间上的不连续变异， 彭兴民等(2012)对 Azadirachta indica 和高张荣等 (2017)对核桃楸(Juglans mandshurica) 的聚类分析结 果也体现出这一规律。本研究中基于分子标记和表 型性状的两种聚类结果的相关性不显著, SSR分子 标记的东北杏种质遗传差异较小, 表型性状多样性 较高, 这是因为除不同种质产地的气候差异外, 海 拔、地形、土壤等方面的环境异质性对表型性状多 样性的形成也起到了重要作用(曾杰等, 2005)。

\section{参考文献}

Bai SQ, Gou WL, Zhang XQ, Zhang XY, Gao R, Liu SG (2002). Ecological characteristics and morphological variations of centipedegrass in different populations. Journal of Beijing Forestry University, 24(4), 97-101. [白史且, 苟文龙, 张新全, 张新跃, 高荣, 刘世贵 (2002). 假俭 草种群变异与生态特性的研究. 北京林业大学学报, 24(4), 97-101.]

Cao Q, Liao K, Liu J, Sun Q, Liu H, Feng BB (2015). Analysis of Daxigou wild apricot genetic diversity in Xinjiang based on ISSR molecular markers. Xinjiang Agricultural Sciences, 52, 1600-1606. [曹倩, 廖康, 刘娟, 孙琪, 刘 欢, 冯贝贝 (2015). 基于ISSR 分子标记分析新疆野杏
遗传多样性. 新疆农业科学, 52, 1600-1606.]

Diao SF, Shao WH, Jiang JM, Dong RX, Sun HG (2014). Phenotypic diversity in natural populations of Sapindus mukorossi based on fruit and seed traits. Acta Ecologica Sinica, 34，1451-1460. [ ]松锋, 邵文豪, 姜景民, 董汝 湘, 孙洪刚 (2014). 基于种实性状的无患子天然群体表 型多样性研究. 生态学报, 34, 1451-1460.]

Gao ZY, Zhang HF, Chen GP, Feng XM, Zhao TJ, Gao X, Shi FC (2017). Fruit stone morphology and geographic variation in Juglans mandshurica populations. Chinese Journal of Applied and Environmental Biology, 23, 609-615. [高 张䒯, 张海峰, 陈国平, 冯小梅, 赵铁建, 高鍂, 石福臣 (2017). 核桃楸种群果核形态及地理变异. 应用与环境 生物学报, 23, 609-615.]

Guo Q, Li XY, Dong L, Cao S, Feng Y, Sun YH, Wen YZ, Niu DS, Liu JP, Yang ZH, Li Y (2019). Analysis of leaf phenotypic diversity of Robinia pseudoacia germplasm resources in Shanxi. Molecular Plant Breeding, 17, 4479-4487. [郭琪, 李秀宇, 董黎, 曹森, 冯玥, 孙宇涵, 文彦忠, 牛东升, 刘佳平, 杨志恒, 李云 (2019). 山西 刺槐种质资源的叶片表型多样性分析. 分子植物育种, 17, 4479-4487.]

He QH, Yang SZ, Li YG, Shen X, Liu XH (2018). Phenotypic variations in seed and fruit traits of Liquidambar formosana populations. Chinese Journal of Plant Ecology, 42, 752-763. [何庆海, 杨少宗, 李因刚, 沈傘金, 柳新红 (2018). 枫香树种群种子与果实表型性状变异分析. 植 物生态学报, 42, 752-763.]

Ji ZF (2013). Study on Phenotypic Diversity of Natural Population in Acer mono Maxim in Shanxi. Master degree dissertation, Shanxi Normal University, Linfen, Shanxi. [姬志峰 (2013). 山西五角枫天然种群表型多样性研究. 硕士学 位论文, 山西师范大学, 山西临汾.]

Jin L, Liu MG, Dong SJ, Wu YL, Zhang X (2018). Genetic diversity and fingerprints of 97 Armeniaca sibiria clones based on SSR markers. Scientia Silvae Sinicae, 54(7), 51-61. [金玲, 刘明国, 董胜君, 吴月亮, 张欣 (2018). 97个山杏无性系的遗传多样性及SSR指纹图谱. 林业科 学, 54(7), 51-61.]

Kundu SK, Tigerstedt PMA (1997). Geographical variation in seed and seedling traits of neem (Azadirachta indica A. Juss.) among ten populations studied in growth chamber. Silvae Genetica, 46, 129-137.

Lei ML, Yang ZD, Dong SJ, Ma FW, Wu YL (2012). Studies on variabilities of quantitative characters and correlation with economic character of Armeniaca vulgaris seedlings in Pengyang County of Ningxia. Northern Horticulture, (12), 21-24. [雷鸣雷, 杨正德, 董胜君, 马发旺, 吴月亮 (2012). 宁夏彭阳县山杏群体数量性状变异及其与经济 性状的相关性. 北方园艺, (12), 21-24.]

Li JH, Peng GQ, Yang DM (2017). Effect of stem length to stem slender ratio of current-year twigs on the leaf display 
efficiency in evergreen and deciduous broadleaved trees. Chinese Journal of Plant Ecology, 41, 650-660. [李俊慧, 彭国全, 杨冬梅 (2017). 常绿和落叶阔叶物种当年生小 枝茎长度和茎纤细率对展叶效率的影响. 植物生态学 报, 41, 650-660.]

Li JR, Song T (2013). Effects of different branch bending angles on the canopy microclimate and growth and fruiting of Luntai white apricot. Northern Horticulture, (20), 13-16. [李军如, 宋涛 (2013). 不同主枝开张角度下轮 台白杏树冠微域气候及生长结果差异分析. 北方园艺, (20), 13-16.]

Li M, Zhao Z, Yang JA, Lu B (2011a). Genetic diversity analysis on germplasm of Armeniaca sibirica in different counties in Loess Plateau. Journal of Northwest A \& F University (Natural Science Edition), 39(2), 143-149, 156. [李明, 赵忠, 杨吉安, 卢斌 (2011a). 黄土高原不同县域山杏 种质遗传多样性研究. 西北农林科技大学学报(自然科 学版), 39(2), 143-149, 156.]

Li M, Zhao Z, Yang JA, Lu B, Miao XJ (2011b). Classification on germplasm resources of Armeniaca sibirica in the Loess Plateau. Journal of Northwest Forestry University, 26(1)，8-12. [李明, 赵忠, 杨吉安, 卢斌, 苗兴军 (2011b). 黄土高原山杏种质资源分类研究. 西北林学院 学报, 26(1), 8-12.]

Li M, Zheng Y, Guo YR, Cheng L, Lu HD, Guo BQ, Zhong QL, Cheng DL (2017). Scaling relationships between twig size and leaf size of Pinus hwangshanensis along an altitudinal gradient in Wuyi Mountains, China. Chinese Journal of Applied Ecology, 28, 537-544. [李曼, 郑媛, 郭英荣, 程林, 卢宏典, 郭炳桥, 钟全林, 程栋梁 (2017). 武夷山不同海拔黄山松枝叶大小关系. 应用生 态学报, 28, 537-544.]

Li WY, Gu WC (2005). Study on phenotypic diversity of natural population in Quercus mongolica. Scientia Silvae Sini$c a e, 41(1), 49-56$. [李文英, 顾万春 (2005). 蒙古栎天然 群体表型多样性研究. 林业科学, 41(1), 49-56.]

Liao BY, Chen LJ, Wang F, He X, Liu MQ, Chen HB, Ren Y, Chen XY (2016). Trend surface analysis of provenance geographic variation of Melia azedarach stone and seed. Forest Research, 29, 784-792. [廖柏勇, 陈丽君, 王芳, 何霞, 刘明骞, 陈涵斌, 任颖, 陈晓阳 (2016). 苦楝种 源果核和种子性状地理变异的趋势面分析. 林业科学 研究, 29, 784-792.]

Lin W, Zhou P, Zhou XB, Wu LY, Zhao YX, Zhao S, Chen $X Y$ (2016). Geographic variation in seed traits of different Zenia insignis provenances. Journal of South China Agricultural University, 37(4), 69-74. [林玮, 周鹏, 周祥斌, 吴林瑛, 赵艳新, 赵帅, 陈晓阳 (2016). 任豆种源种子 性状地理变异研究. 华南农业大学学报, 37(4), 69-74.]

Liu HZ, Zhu H, Guo CL, Xia DA (1997). Study on the provenance of Fraxinus mandshurica. Journal of Forestry Research, 8, 10-12.
Liu JQ, Yin MY, Zuo SY, Yang SB, Wuyun T (2017). Phenotypic variations in natural populations of Amygdalus pedunculata. Chinese Journal of Plant Ecology, 41, 1091-1102. [柳江群, 尹明宇, 左丝雨, 杨绍斌, 乌云塔 娜 (2017). 长柄扁桃天然种群表型变异. 植物生态学 报, 41, 1091-1102.]

Liu MG, Li M, Wu YL, Dong SJ (2015). Study on pollen morphological characteristics and its relationship with pollen germination in Armeniaca sibirica. Journal of Shenyang Agricultural University, 46, 166-172. [刘明国, 李民, 吴 月亮, 董胜君 (2015). 山杏花粉形态特征与花粉萌发的 关系. 沈阳农业大学学报, 46, 166-172.]

Liu MG, Zhao GL, Dong SJ (2006). Analysis of peroxidase isoenzyme and seed soluble protein in Armeniaca sibiria. Journal of Shenyang Agricultural University, 37, 582-586. [刘明国, 赵桂玲, 董胜君 (2006). 山杏种内POD同工 酶及种子可溶性蛋白分析. 沈阳农业大学学报, 37, 582-586.]

Liu RL, Hu MJ, Li J, Liu JH (2016). Study on geographic variation of fruit sizes in Vaccinium bracteatum. Nonwood Forest Research, 34(3), 114-120. [刘仁林, 胡明娇, 李 江, 刘江华 (2016). 乌饭树果实大小的地理变异研究. 经济林研究, 34(3), 114-120.]

Liu XL, Gu WY, Wei HB (2015). Survey of walnut germplasm resources in Qinghai Plateau phenotype and diversity analysis of its nut phenotipic. Northern Horticulture, (13), 34-36. [刘小利, 顾文毅, 魏海斌 (2015). 青海高原核 桃种质资源调查及坚果表型多样性分析. 北方园艺, (13), 34-36.]

Liu Y, Chen T, Zhang J, Wang J, Wang H, Tang HR, Wang XR (2016). Genetic diversity analysis of Chinese cherry landraces (Prunus pseudocerasus) based on phenotypic traits. Acta Horticulturae Sinica, 43, 2119-2132. [刘)胤，陈涛, 张静, 王珏, 王浩, 汤浩茹, 王小蓉 (2016). 中国樱桃 地方种质资源表型性状遗传多样性分析. 园艺学报, 43, 2119-2132.]

McDonald PG, Fonseca CR, Overton JM, Westoby M (2003). Leaf-size divergence along rainfall and soil-nutrient gradients: Is the method of size reduction common among clades? Functional Ecology, 17, 50-57.

Nei M, Li WH (1979). Mathematical model for studying genetic variation in terms of restriction endonucleases. Proceedings of the National Academy of Sciences of the United States of America, 76, 5269-5273.

Niklas KJ (1999). A mechanical perspective on foliage leaf form and function. New Phytologist, 143, 19-31.

Pang ZW, Li XY, Zheng Z, Zhao XJ (2001). Cultivation techniques and benefit analysis of Armeniaca mandshurica. Forestry Science \& Technology, 26(5), 48-50. [庞振伟, 李绪尧, 郑重, 赵晓军 (2001). 东北杏栽培技术与效益 分析. 林业科技, 26(5), 48-50.]

Peng XM, Wu JC, Zheng YX, Zhang YP, Li GQ (2012).

www.plant-ecology.com 
Phenotypic variation in cultivated populations of Azadirachta indica in Yunnan, China. Chinese Journal of Plant Ecology, 36, 560-571. [彭兴民, 吴疆独, 郑益兴, 张燕平, 李根前 (2012). 云南引种印楝实生种群的表型 变异. 植物生态学报, 36, 560-571.]

Peng Y, Su ZX, Zhang SL (2008). Detecting genetic diversity by morphological characteristics of leaves and ISSR markers in Citrus grandis. Journal of Northwest A \& F University (Natural Science Edition), 36(4), 104-110. [彭 瑜, 苏智先, 张素兰 (2008). 利用叶片形态学性状和 ISSR标记检测柚类的遗传多样性. 西北农林科技大学 学报(自然科学版), 36(4), 104-110.]

Qin Q, Wang NN, Li JH, Su GC (2016). Diversity and cluster analysis on phenotypic traits and SSR of olive cultivars. Forest Research, 29，676-681. [秦倩, 王楠楠, 李金花, 苏光灿 (2016). 油橄榄品种表型和SSR标记的多样性 及聚类分析. 林业科学研究, 29, 676-681.]

Ren HJ, Feng Z, Qiao Q, An K, Ye MJ, Si FF, Zhang L, Sun ZK (2018). Geographic variation trend of leaf morphology in Acer truncatum. Journal of Northwest Forestry University, 33(1), 113-119. [任红剑, 丰震, 乔谦, 安凯, 叶美 静, 司芬芬, 张林, 孙忠奎 (2018). 元宝枫叶片形态特 征的地理变异. 西北林学院学报, 33(1), 113-119.]

Shao WH, Diao SF, Dong RX, Jiang JM, Yue HF (2013). Study on geographic variation of morphology and economic character of fruit and seed of Sapindus mukorossi. Forest Research, 26, 603-608. [邵文豪, 刀松锋, 董汝湘, 姜景 民, 岳华峰 (2013). 无患子种实形态及经济性状的地理 变异. 林业科学研究, 26, 603-608.]

Su BH, Fan CH, Li GD, Zhang JK, Han MY (2008). Effects of modifying between light distribution, yield and quality of different shapes on "Red Fuji" apple. Journal of Northwest $A \& F$ University (Natural Science Edition), 36(1), 158-162. [苏渤海, 范崇辉, 李国栋, 张军科, 韩明玉 (2008). 红富士苹果改形过程中不同树形光照分布及其 对产量品质的影响. 西北农林科技大学学报(自然科学 版), 36(1), 158-162.]

Su SP, Li Y, Chong PF, Gao Q (2013). Correlation analysis of phenotypic traits of Reaumuria soongorica seed in different natural populations in the Gansu Corridor. Acta Prataculturae Sinica, 22(1), 87-94. [苏世平, 李毅, 种培芳, 高茜 (2013). 河西走廊不同红砂天然群体种子表型性 状相关性研究. 草业学报, 22(1), 87-94.]

Sun RY (2002). Foundations in Ecology. Higher Education Press, Beijing. [孙儒泳 (2002). 基础生态学. 高等教育 出版社, 北京.]

Wan XQ, Zhang F (2013). An overview of Populus genetic resources in southwest China. Forestry Chronicle, 89, 79-87.

Wang LB (2010). Geographic distribution and botanical characters of 3 Armeniaca plant in China. Forest Research, 23, 435-439. [王利兵 (2010). 我国3种杏的地理分布及其
植物学性状. 林业科学研究, 23, 435-439.]

Wang YK, Wu GL, Zhao AL, Li DK (2014). Phenotypic genetic diversity of Jujube germplasm resources. Scientia Silvae Sinicae, 50(10), 33-41. [王永康, 吴国良, 赵爱玲, 李登科 (2014). 䨋种质资源的表型遗传多样性. 林业科 学, 50(10), 33-41.]

Wang Z, Kang M, Liu HB, Gao J, Zhang ZD, Li YY, Wu RL, Pang XM (2014). High-level genetic diversity and complex population structure of siberian apricot (Prunus sibirica $\mathrm{L}$.) in China as revealed by nuclear SSR markers. PLOS ONE, 9, e87381. DOI: 10.1371/journal.pone.0087381.

Wu YL, Liu MG, Dong SJ, Ma FW, Zhao GL, Liu P, Liu QB, Yao LJ, Liu MZ, Liu LX, Yu QF, Fan CZ, Zheng YT, Qin J, Liu Y (2015). DB21/T 2462-2015 Technical Regulations for Investigation and Evaluation of Armeniaca Sibirica Germplasm Resources. Liaoning Supervision Bureau of Quality and Technical, Shengyang. [吴月亮, 刘明 国, 董胜君, 马发旺, 赵桂玲, 刘平, 刘青柏, 姚丽杰, 刘明忠, 刘立新, 于庆福, 焚春志, 郑永涛, 秦静, 刘勇 (2015). DB21/T 2462-2015 山杏种质资源调查及评价 技术规程. 辽宁省质量技术监督局，沈阳.]

Wu YL, Yi GJ, Zhou BR, Zeng JW, Huang YH (2007). The advancement of research on litchi and longan germplasm resources in China. Scientia Horticulturae, 144(3), 143-150.

Yang XX, Leng PS, Zheng J, Hu ZH, Liu XY, Yang XH, Dou DQ (2016). Variation of phenotypic traits of seed and seedling of Syringa reticulata subsp. amurensis from different provenances and their correlations with geographicclimatic factors. Journal of Plant Resources and Environment, 25(3), 80-89. [杨晓霞, 冷平生, 郑健, 胡增辉, 刘 学娅, 杨晓红, 窦德泉 (2016). 暴马丁香不同种源种子 和幼苗的表型性状变异及其与地理-气候因子的相关性. 植物资源与环境学报, 25(3), 80-89.]

Yin J, Dong SJ, Wu Z, Liu MG, Wu YL, Yu QF, Zhong WP (2015). Quantitative classification of germplasm resources of Armeniaca sibiria at Zhalantun region of Inner Mongolia. Nonwood Forest Research, 33(3), 75-80. [尹健，董胜 君, 吴智, 刘明国, 吴月亮, 于庆福, 仲维平 (2015). 内 蒙古扎兰屯地区西伯利亚杏种质资源的数量分类. 经 济林研究, 33(3), 75-80.]

Zeng J, Zheng HS, Gan SM, Bai JY (2005). Phenotypic variation in natural populations of Betula alnoides in Guangxi, China. Scientia Silvae Sinicae, 41(2), 59-65. [曾杰, 郑海 水, 甘四明, 白嘉雨 (2005). 广西西南桦天然居群的表 型变异. 林业科学, 41(2), 59-65.]

Zhai LJ, Shi QQ, Li X, Luo XN, Niu LX, Zhang YL (2019). Analysis of genetic diversity of tree peony in Wanhua Mountain in Yan'an City based on phenotypic traits and conserved DNA-derived polymorphism markers. Jiangsu Agricultural Sciences, 47(2), 95-101. [翟立娟, 史倩倩, 李想, 罗小宁, 牛立新, 张延龙 (2019). 基于表型性状 
CDDP分子标记延安万花山牡丹遗传多样性分析. 江苏 农业科学, 47(2), 95-101.]

Zhang JY, Zhang Z (2003). Chinese Fruit Tree, Apricot. China Forestry Publishing House, Beijing. [张加延, 张钊 (2003). 中国果树志, 杏卷. 中国林业出版社, 北京.]

Zhao HJ, Liu WS, Li N, Zhang YP, Zhang QP, Liu S (2013). Variation and probability grading of main quantitative traits of apricot (Armeniaca vulgaris) germplasm. Journal of Fruit Science, 30, 37-42. [赵海娟, 刘威生, 刘宁, 张 玉萍, 章秋平, 刘硕 (2013). 普通杏(Armeniaca vulgaris) 种质资源果实主要数量性状变异及概率分级. 果树 学报, 30, 37-42.]

Zheng Z, Li YR, Zhang SB, Duan WP, Zhang YP (2007). Influence of the altitudinal increase on water and humidity conditions Xishuangbanna. Journal of Mountain Science, 25, 33-38. [郑征, 李佑荣, 张树斌, 段文平, 张一平
(2007). 西双版纳海拔变化对水湿状况的影响. 山地学 报, 25, 33-38.]

Zhong WP, Dong SJ, Liu MG, Wu YL, Yu QF, Yin J (2015). Study on the population traits of Armeniaca sibirica in Zhalantun County of Inner Mongolia. Northern Horticulture, (11), 34-36. [仲维平, 董胜君, 刘明国, 吴月亮, 于 庆福, 尹健 (2015). 内蒙古扎兰屯地区山杏群体性状研 究. 北方园艺, (11), 34-36.]

Zhu H, Zhu SX, Li YF, Yi XG, Duan YF, Wang XR (2018). Leaf phenotypic variation in natural populations of Cerasus dielsiana. Chinese Journal of Plant Ecology, 42, 1168-1178. [朱弘, 朱淑霞, 李涌福, 伊贤贵, 段一凡, 王贤荣 (2018). 尾叶樱桃天然种群叶表型性状变异研 究. 植物生态学报, 42, 1168-1178.]

责任编委：何维明 责任编辑：李 敏 实习编辑：赵 航

附录I 东北杏种质99个SSR位点的多态性信息

Supplement I Polymorphism information of 99 SSR loci in Armeniaca mandshurica germplasms http://www.plant-ecology.com/fileup/1005-264X/PDF/cjpe.2019.0060-S1.pdf 
徐豪, 刘明国, 董胜君, 吴月亮, 张皓凯 (2019). 东北杏种质资源多样性及其地理变化. 植物生态学报, 43, 585-600. DOI: 10.17521/cjpe.2019.0060

Xu H, Liu MG, Dong SJ, Wu YL, Zhang HK (2019). Diversity and geographical variations of germplasm resources of Armeniaca mandshurica. Chinese Journal of Plant Ecology, 43, 585-600. DOI: 10.17521/cjpe.2019.0060

http://www.plant-ecology.com/CN/10.17521/cjpe.2019.0060

附录I 东北杏种质 99 个 SSR 位点的多态性信息

Supplement I Polymorphism information of 99 SSR loci in Armeniaca mandshurica germplasms

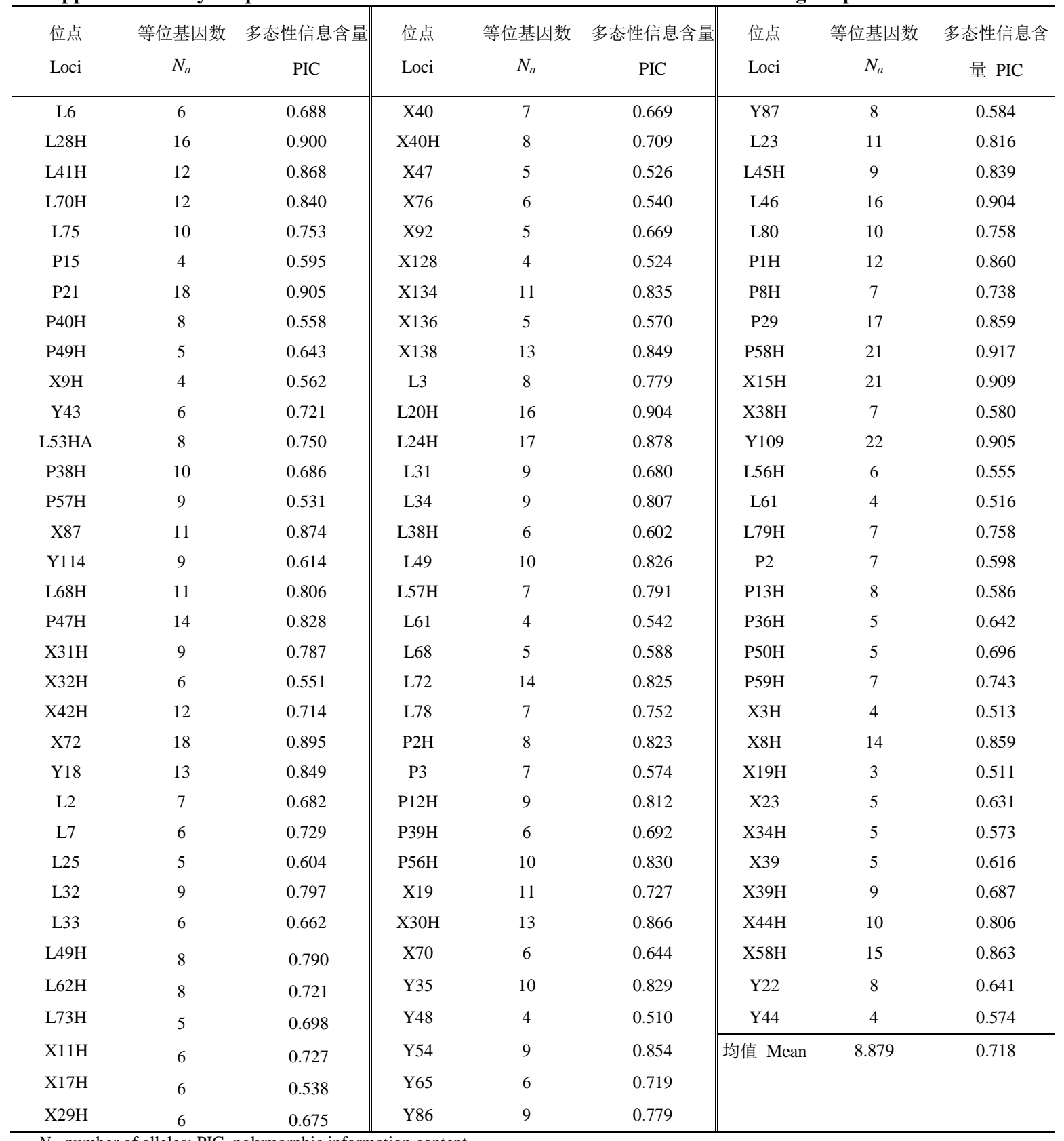

$N_{a}$, number of alleles; PIC, polymorphic information content. 